San Jose State University

SJSU ScholarWorks

Master's Theses

Master's Theses and Graduate Research

1998

\title{
Evaluation of exercise videotapes performed by fitness experts and celebrities
}

Adrienne Robinson

San Jose State University

Follow this and additional works at: https://scholarworks.sjsu.edu/etd_theses

\section{Recommended Citation}

Robinson, Adrienne, "Evaluation of exercise videotapes performed by fitness experts and celebrities" (1998). Master's Theses. 1789.

DOI: https://doi.org/10.31979/etd.rspv-s33g

https://scholarworks.sjsu.edu/etd_theses/1789

This Thesis is brought to you for free and open access by the Master's Theses and Graduate Research at SJSU ScholarWorks. It has been accepted for inclusion in Master's Theses by an authorized administrator of SJSU ScholarWorks. For more information, please contact scholarworks@sjsu.edu. 


\section{INFORMATION TO USERS}

This manuscript has been reproduced from the microfilm master. UMI films the text directly from the original or copy submitted. Thus, some thesis and dissertation copies are in typewriter face, while others may be from any type of computer printer.

The quality of this reproduction is dependent upon the quality of the copy submitted. Broken or indistinct print, colored or poor quality illustrations and photographs, print bleedthrough, substandard margins, and improper alignment can adversely affect reproduction.

In the unlikely event that the author did not send UMI a complete manuscript and there are missing pages, these will be noted. Also, if unauthorized copyright material had to be removed, a note will indicate the deletion.

Oversize materials (e.g., maps, drawings, charts) are reproduced by sectioning the original, beginning at the upper left-hand comer and continuing from left to right in equal sections with small overlaps. Each original is also photographed in one exposure and is included in reduced form at the back of the book.

Photographs included in the original manuscript have been reproduced xerographically in this copy. Higher quality $6 " \times 9$ " black and white photographic prints are available for any photographs or illustrations appearing in this copy for an additional charge. Contact UMI directly to order.

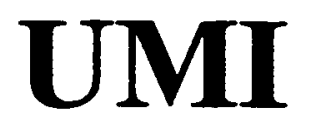

A Bell \& Howell Information Company 


\title{
NOTE TO USERS
}

\section{The original manuscript received by UMI contains pages with slanted print. Pages were microfilmed as received.}

This reproduction is the best copy available

\author{
UMI
}



EVALUATION OF EXERCISE VIDEOTAPES PERFORMED BY FTTNESS

EXPERTS AND CELEBRITIES

\begin{abstract}
A Thesis
Presented to

The Faculty of the Department of Human Performance

San Jose State University
\end{abstract}

In Partial Fulfillment

of the Requirements for the Degree

Master of Arts

by

ADRIENNE ROBINSON

December 1998 
UMI Number: 1393196

UMI Microform 1393196

Copyright 1999, by UMI Company. All rights reserved.

This microform edition is protected against unauthorized copying under Title 17, United States Code.

\section{UMI \\ 300 North Zeeb Road \\ Ann Arbor, MI 48103}




\section{Copyright 1998}

Adrienne Robinson

ALL RIGHTS RESERVED 
APPROVED FOR THE DEPARTMENT OF HUMAN PERFORMANCE

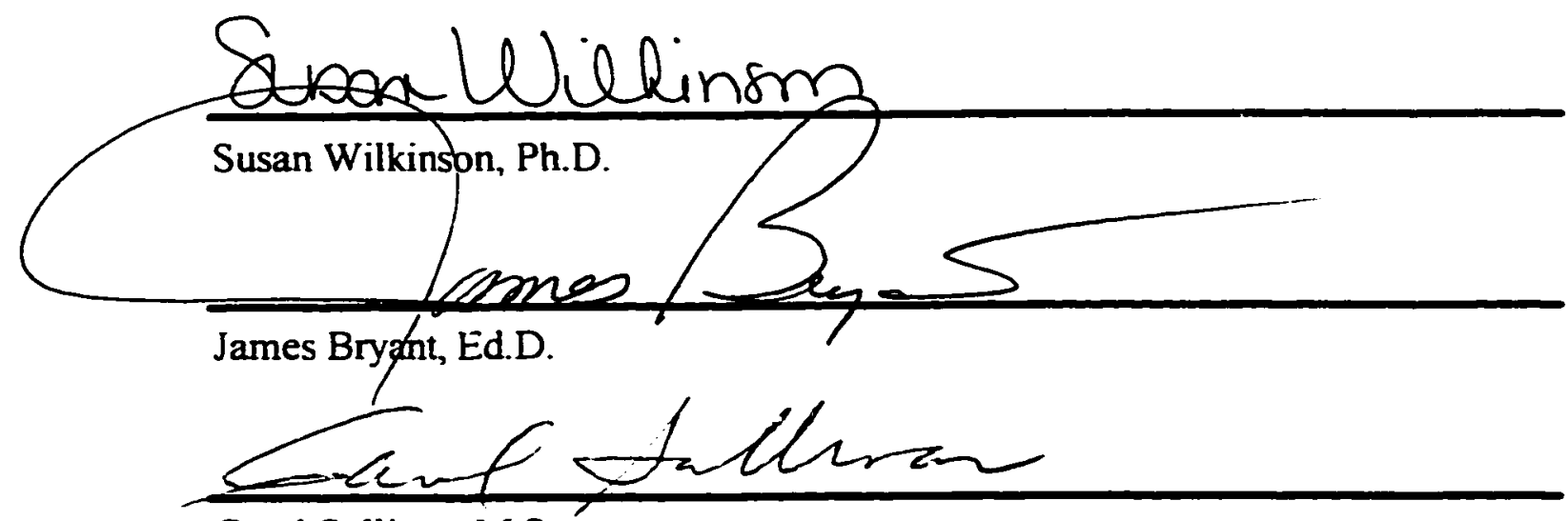

Carol Sullivan, M.S.

APPROVED FOR THE UNIVERSITY

Willian Zis 


\section{EVALUATION OF EXERCISE VIDEOTAPES PERFORMED BY FITNESS EXPERTS AND CELEBRITIES}

by Adrienne Robinson

The study evaluated resistance training exercise videotapes performed by fitness experts and celebrities to determine their accuracy, safety, and usefulness for the general public. An evaluation instrument was developed by the researcher to conduct a critique of each exercise videotape. The videotapes were selected from popular major videostores in a large metropolitan area. A total of eight videotapes were reviewed, five of celebrities and three of fitness experts. Using the Video Critique, the researcher analyzed the teaching ability of the instructor and the appropriateness of the exercises.

Comparisons were made between the celebrity and fitness expert groups. The celebrities were shown to have a longer warm-up and cooldown. Although the celebrities provided more comprehensive exercises in this area, the fitness experts were more technically skilled than the celebrities in their presentation of the exercises. Comparisons revealed that the fitness experts and the celebrities provided safe workouts in their exercise videotapes. 


\section{ACKNOWLEDGMENTS}

The preparation of this thesis document has been the work of many people, without whom this would not have been possible. I wish to thank an unmentionable number of friends who constantly reminded me that I had an important project to finish. I thank Katherine McHale for her help and support, especially with her vast computer knowledge that helped me transfer my document onto my new computer. Thank you to Teri Wexted for her assistance in the development of the Video Critique. I thank Dr. Susan Wilkinson for not giving up on me, for teaching me, guiding me, and encouraging me to do my best. I also thank her for infinite wisdom and uncanny insight. I thank Carol Sullivan for being a part of my team and a big supporter of mine. I thank Dr. James Bryant, who motivated me to enroll at San Jose State University in the first place. Thank you for pushing me in the right direction. You all have been very instrumental in my success here, and I deeply thank you all. 
TABLE OF CONTENTS

Abstract iv

Acknowledgments $\quad$ v

$\begin{array}{ll}\text { List of Tables } & \text { ix }\end{array}$

List of Figures $\quad \mathbf{x}$

CHAPTER $\quad$ Page

I. INTRODUCTION I

$\begin{array}{ll}\text { Purpose } & 5\end{array}$

Delimitations $\quad 5$

$\begin{array}{lr}\text { Limitations } & 6\end{array}$

$\begin{array}{ll}\text { Definition of Terms } & 6\end{array}$

2. REVIEW OF LITERATURE 9

$\begin{array}{ll}\text { The Physiological Benefits of Weight Training } & 10\end{array}$

The Role of Resistance Training in Disease Prevention 13

$\begin{array}{ll}\text { The Psychological Benefits of Resistance Training } & 16\end{array}$

$\begin{array}{ll}\text { The Social Aspects of Resistance Training } & 17\end{array}$

$\begin{array}{lr}\text { The Influence of Mass Media } & 18\end{array}$

Summary $\quad 21$

3. METHODS 23

$\begin{array}{ll}\text { Introduction } & 23\end{array}$

$\begin{array}{ll}\text { Selection of Videotapes } & \mathbf{2 3}\end{array}$ 
Instrumentation

Interobserver Agreement of Video Critique $\quad 26$

$\begin{array}{ll}\text { Data Collection } & 27\end{array}$

4. RESULTS \& DISCUSSION 29

Data Analysis $\quad 30$

$\begin{array}{ll}\text { Warm-Up: Active Phase } & 31\end{array}$

Warm-Up: Stretch Phase $\quad 35$

$\begin{array}{ll}\text { Overall Presentation } & 38\end{array}$

$\begin{array}{ll}\text { Exercise Phase } & 40\end{array}$

$\begin{array}{ll}\text { Cooldown/Stretch Phase } & 43\end{array}$

$\begin{array}{ll}\text { Overall Exercise Selection } & 46\end{array}$

$\begin{array}{ll}\text { Overall Presentation } & 48\end{array}$

General Comments $\quad 51$

Summary of Celebrity and Fimess Expert $\quad 54$

Summary of Top Ranked Videotapes $\quad 55$

5. CONCLUSIONS, SUMMARY \& RECOMMENDATIONS 59

$\begin{array}{lr}\text { Summary } & 59\end{array}$

$\begin{array}{lr}\text { Conclusions } & 60\end{array}$

$\begin{array}{ll}\text { Recommendations for Future Research } & 61\end{array}$

$\begin{array}{ll}\text { REFERENCES } & 63\end{array}$ 
A. Video Critique 


\section{LIST OF TABLES}

Page

Table 1 Mean Time in Minutes and Seconds for the Warm-up, Exercise, and Stretch Phase for the Celebrity and Fitness

Expert Groups

Table 2 Mean and Individual Presentation of the Number of

Stretches Performed and Execution Rating of the Celebrity and Fitness Expert Group in the Warm-up Phase

Table 3 Number and Length of Exercises and Mean Rating for the Celebrity and Fitness Expert Groups for Components Evaluated During the Exercise Phase

Table 4 Inclusion of the Necessary Components of the

Cooldown/Stretch Phase and Times for the Celebrity and

Fitness Expert Groups

Table 5 Overall Exercise Selection Scores for the Celebrity and Fitness Expert Groups of the Exercise Phase 


\section{LIST OF FIGURES}

Page

Figure 1 Mean Rating for Each Variable of the Active Phase

of the Warm-up 34

Figure 2 Mean Rating for Each Variable Included in the Overall

Presentation of the Warm-up $\quad 39$

Figure 3 Mean Ratings for All Variables in the Overall Presentation

of the Exercise Phase $\quad 49$ 


\section{CHAPTER I}

\section{Introduction}

It has been documented in the literature that the benefits of exercise are numerous; not only the physiological benefits, but also the emotional, psychological, and mental benefits. The physiological benefits are far reaching. Those who exercise benefit from increased stamina and energy, achievement of normal blood pressure and cholesterol levels, increased muscle tone, stronger bones, lower body fat and higher lean body mass. Exercise also slows the aging process by keeping bones healthy, the heart in good condition, and aids in relieving the stresses of everyday life that can lead to disease.

The benefits of cardiovascular exercises, specifically, are also well documented. In fact, most studies show a strong correlation between exercise and the subsequent health benefits gained from cardiovascular conditioning. Strength training exercises have also been shown to have a significant impact on one's physical fitness level. Strength training has been directly related to increased bone density and helps to stave off a debilitating disease, osteoporosis. Improving one's physical fitness level also improves one's ability to carry out daily tasks. This is due largely in part to the increased energy derived from exercise (Kravitz, 1992), which can be achieved by increasing muscular strength and endurance. Muscle tone, defined as increasing muscle strength and endurance, is a term often used in the fitness industry. However, muscle tone carries different connotations for different people. Muscle tone is most often equated with a well defined, or sculpted musculature requiring substantial weightlifting with many hours of dedication. Many define muscle tone as muscular strength or endurance where the ratio of lean body mass (LBM) percentage to body fat percentage is very high. Muscle tone, therefore, is a body high in lean body mass and low in subcutaneous body fat. Although muscle tone can be attained in numerous ways, it is best achieved by a 
consistent resistance training program while maintaining a sound and consistent aerobic training program.

Inactivity has reached epidemic proportions in this country. Less than 22 percent of all American adults are physically active and over half are totally sedentary (UCB Wellness Letter, Nov., 1993). In 1990 The American College of Sports Medicine (ACSM), recommended that individuals exercise strenuously for at least 20 minutes three to five times a week. However, data clearly demonstrate that 80 percent of the American population are not active. According to the UCB Wellness Letter, (Nov., 1993), ACSM, in response to the high levels of inactivity, reconsidered their guidelines. ACSM now recommends that any activity, be it housework or gardening, done sporadically or continuously, throughout the day totaling 30 minutes is sufficient for the purpose of warding off life threatening and debilitating diseases (UCB Wellness Letter, Nov., 1993). Low to moderate levels of physical fitness are a significant risk factor in preventing all-cause mortality, cardiovascular disease, and cancer in both men and women. In a study by Blair et al., (1989), men who have high cholesterol and blood pressure levels but were also physically fit had a reduced risk of chronic disease over those men who were sedentary. ACSM guidelines simply encourage people to be active. Because there is a difference between being physical fit and being healthy, the prescription for exercise to achieve either differs accordingly (ACSM, 1991). Those who desire to be physically fit need to engage in more moderate to intense activity. The revised ACSM guidelines are based on current research that suggests that any kind of physical activity, even light activity, will help prevent diseases. This new evidence is encouraging. According to the UCB Wellness Letter, (Nov., 1993), the previous guidelines may have been too strict. Americans, recognizing that they could not participate in 30 minutes of strenuous exercise decided they would not participate at all (UCB Wellness Letter, Nov., 1993). 
More moderate to intense types of exercise, of course, are more beneficial by providing an even greater amount of the physiological benefits necessary to keep one physically fit and healthy.

Agencies governing health and fitness such as the ACSM along with the Centers for Disease Control and Prevention, and the President's Council on Physical Fitness and Sports consider inactivity one of the greatest causes of disease in the United States. Such organizations claim that inactivity is as harmful to the nation's health as smoking and high cholesterol levels. McGinnis (1992) stated that physical inactivity ranks second in the leading causes of death in the country; tobacco use ranks first. Ironically, these two factors also represent the two leading preventable contributors to death. Physical activity in and of itself appears to be a significant factor in preventing death and disease. Paffenbarger et al. (1986) found in their longitudinal study that as physical activity increased from $500 \mathrm{kcal} / \mathrm{wk}$ to $3500 \mathrm{kcal} / \mathrm{wk}$ the death rate decreased. This remained true with or without considering smoking, hypertension, or extreme body weight. Mortality risks decreased by an additional 24 percent when smoking, hypertension, and extreme body weight were eliminated. Adequate exercise was ascribed to adding one to two years of additional life compared to sedentary counterparts.

As stated earlier, most studies that have discussed the health benefits derived from exercise are, for the most part, referring to cardiovascular conditioning. The physiological changes that occur through a cardiovascular conditioning program include but are not limited to a decreased resting heart rate, decreased blood pressure, especially for the hypertensive individual, and reduced cholesterol levels. Stroke volume increases as well as cardiac output (Mersy, 1991; McArdle, Katch \& Katch, 1991). The psychological benefits associated with exercise include decreased anxiety and stress, a reduction of depression, and decrease in fatigue and tension (Mersy, 1991). These 
training benefit adaptations aid to decrease the risk of cardiovascular disease and improve the quality of an individual's life. The benefits of aerobic exercise are so overwhelming that numerous research projects have been conducted but unfortunately, leave research on resistance training untested. The attention that researchers, and hence the media, have given to aerobic exercise could also be another reason that so many people are so strongly drawn toward it as their choice of daily exercise. However, the benefits of muscular strength and endurance cannot be overlooked. Muscular strength and endurance do not directly improve cardiorespiratory fitness levels and therefore should not be used as a method of achieving improved aerobic capabilities (ACSM, 1991). This fact further substantiates the importance of aerobic exercise, and for all the reasons heretofore discussed. However, resistance training also needs to be addressed and considered an integral part of a fitness program for overall health and well-being (ACSM, 1991).

Americans have many choices available to them to maintain good health and prevent diseases, all of which can be seen frequently in newspapers and magazines, and on television. The public display of exercise poses interesting challenges for fitness professionals, exercise physiologists, and educators since many advertisements and products may not necessarily be based on research findings. Trained professionals are searching to find ways to encourage people to exercise more if only to exercise minimally. In fact, the greatest challenge of physical educators and the like is to motivate the sedentary population to a life of exercise.

The obstacles Americans create for engaging in physical activity are numerous. The most frequently heard excuses are time and convenience. Since a good overall fitness program includes both cardiovascular exercise and resistance training, combining the two takes even greater effort, more time and forethought. In conjunction with this, 
exercise is not always perceived as fun. If exercise were easy to do, it would be more desirable and popular. Once someone decides to make the time for exercise, making it convenient becomes an important consideration. Two popular exercise programs that are convenient for most people are workout videotapes and the use of home fitness equipment. What could be more convenient that exercising in the privacy and comfort of one's own home?

\section{Purpose}

This study evaluated and compared fitness expert and celebrity resistance training exercise videotapes to determine their safety, usefulness, and accuracy of training principles. A selection of videotapes was chosen from those available to the public where celebrities and fitness experts in the field of exercise provided instruction. An evaluation instrument, the Video Critique, was developed to evaluate a random sample of workout videotapes currently available on the market and used by the public for exercise. This study evaluated the essential training components of the exercise videotapes.

Recommendations have been made for the development of resistance training exercise videotapes that maintain useful, safe, and accurate training principles. The components of the "best" videotapes were assessed and discussed.

\section{Delimitations}

The delimitations of this study include the following:

1. The celebrities of the videotapes chosen were not required to have published a previous videotape.

2. The fitness experts of the videotapes chosen were required to have been certified by a fitness certifying body for at least two years.

3. The fitness experts had to be certified by any one of three exercise instructor certification agencies, American Council on Exercise, American College of Sports 
Medicine, and the Aerobic and Fitness Association of America.

4. The videotapes included only those that involved resistance training during some portion of the workout.

\section{Limitations}

The limitations of this study include the following:

1. Since the study focused on public access, the videotapes reviewed were limited to those that could be found at chain stores or very large video stores.

2. The videotapes evaluated were chosen from videostores found within a large city and/or metropolitan area.

3. The study only included exercise videotapes of women.

4. The interobserver agreement is limited to one observer who evaluated one randomly selected exercise videotape.

5. The evaluation of the exercise videotapes reviewed were limited to the Video Critique developed by the researcher.

\section{Definition of terms}

Active Phase - The portion of the warm-up that involves low intensity movements for the purpose of elevating the body temperature and circulating blood to the joints to prepare the body for stretching and more intense exercise.

Alignment - maintaining a neutral posture while standing, sitting, or lying in a supine or prone position. A neutral posture occurs when the natural curve of the spine is maintained. A normal position must also be maintained from the hip, knee, and ankle. Celebrity - any person who is classified as famous, well known, or well publicized, such as a movie star, model, television show hosthostess, sports figure, Miss America, Ms. or Mr. Olympia or political figure.

Choreography - the sequence and arrangement of dance or exercise movements chosen to 
create a specific look or feel.

Cooldown - the portion of the workout designed to recover the heart rate to normal and relax the body.

Cueing - calling out a particular stretch, exercise, or motion desired for the clientele to execute in a timely manner.

Execution - the control and the range of motion demonstrated during the performance of the exercises and movements.

Fitness Expert - a certified instructor through one or more of the three nationally recognized bodies of instructor certification, (American Council on Exercise [ACE], Aerobic Fitness Association of America [AFAA], or the American College of Sports Medicine $[\mathrm{ACSM}])$.

Form - the manner in which movements are executed with large emphasis on body alignment and control, as well as the precision with which they are executed.

Muscular strength - the maximum amount of force a muscle or muscle group can generate against a resistance (McArdle et al., 1991).

Muscular endurance - the amount of force a muscle or muscle group can generate over an extended period of time (Kravitz, 1992).

Resistance - any force that acts in opposition to the force of muscular contractions.

Resistance training: any method that overloads the skeletal muscle so that it imparts a change to improve muscular strength and/or endurance.

Stretch - the action of lengthening skeletal muscles beyond their normal resting condition.

Transition - the movement that occurs when going from one exercise, stretch, or body position to another.

Unsupported forward flexion - bending the trunk greater than 50 degrees without placing 
hands on thighs for lower back support against the pull of gravity. 


\section{CHAPTER II}

\section{REVIEW OF LTERATURE}

The review of literature is divided into subsections including (1) the physiological benefits of weight training, (2) the role of resistance training in disease prevention, (3) psychological benefits of resistance training, (4) the social aspects of resistance training and $(5)$ the influence of mass media.

\section{Literature related to resistance training}

Resistance training is a form of exercise whereby one can achieve or enhance muscular strength and/or muscular endurance. Muscular strength is defined as the maximum amount of force that can be produced by a muscle or muscle group (McArdle et al., 1991). In addition, Kosich (1994) defines muscular strength as the ability to generate force and further distinguishes strength from power by defining power as the ability to move a great amount of weight quickly. Any exercise that increases the force a muscle can exert against a resistance increases muscular strength (Cinque, 1990).

Therefore, strength training uses resistance to improve one's ability to either resist or exert force (Baker, 1994).

In contrast, muscular endurance is defined as any exercise that can be performed over an extended period of time. The force exerted is not maximal but does require strength and power (Kravitz, 1992). Muscular endurance is reflected in the duration of time muscular force can be applied through either isometric contractions or concentric and eccentric contractions (McArdle et al., 1991). Kosich (1994) described endurance as it affects an individual's life and lifestyle. He stated that endurance is not limited to or simply a function of how long one can sustain an exercise, but that endurance reflects the ability to support one's musculature to sustain body weight for $80-90$ years. Therefore, 
endurance training improves one's ability to maintain a contraction or endure numerous repetitions of work (Baker, 1994). Many daily leisure and occupational tasks involve lifting or holding heavy objects. Maintaining muscular strength and endurance enables one to perform simple tasks with less physiological stress (ACSM, 1991).

Research has suggested that weight training be prescribed as a tool to maintain and improve general and overall fitness (Cinque, 1990; ACSM, 1991). Resistance training is also recommended not only to maintain one's body weight but to lose weight (Cinque, 1990). Baker (1994) stated that weight training is limited to exercises that only use barbells and dumbbells for the purpose of improving strength or endurance of the muscles. Resistance training, on the other hand, uses many different modalities including bands, tubing, and partner exercise (Baker, 1994). McArdle et al. (1991) stated that weight lifting is resistance training and that it happens to be the most popular form of resistance training.

Popular fitness magazines such as those found on most magazine racks attempt to educate the public in understanding the dynamics of weight training. Those magazines further attempt to unravel the myriad of details necessary for proper and safe weight training methods. The intentions are honorable, the information most often accurate. However, some popular magazines perpetuate the unrealistic fantasy so prevalent in today's society of attaining a perfect body. Many seek to attain "body beautiful". This obsession "to be thin" is used by some magazines as the catch from which to make the sale. Though the information they report may be accurate, the image they continue to portray is unfair and inaccurate to the readers. The physiological benefits of resistance training

Americans involve themselves in physical activity for many reasons. Physical appearance is the primary reason many people become involved in physical activity 
(Baker, 1994). Other people get involved in exercise for medical reasons, either because they could be facing a potential medical disaster or recently survived a traumatic or potentially serious medical problem and were instructed to begin a health and fitness program. Some may participate in an exercise program because they are recovering from an injury and exercise was recommended for rehabilitation or to prevent the reoccurrence of the injury. Some people become active because they believe it is the right thing to do. Whatever the reason, a weight training program is very important in an overall fitness program (ACSM, 1991). Research shows that the use of weights is the method consistently recommended to change and improve the shape of the body (McArdle et al., 1991). Though a common motivational factor for most people who participate in a weight training program is a "sculpted body", the benefits of weight training go far beyond this simplistic outcome.

Many different protocols are available for designing a weight training program. A participant can choose from a low intensity, moderate intensity, or a high intensity program. Different intensity programs can be combined on a weekly basis or on an alternating basis throughout the year. Fitness goals or physical body style goals significantly affect the protocol selection. The program choices seem endless but when the ultimate goal is to choose an exercise program that strengthens a specific target muscle or muscle groups then overcoming a fixed resistance is requisite (McArdle et al., 1991).

The strengthening process will increase muscle circumference. Although resistance training increases muscle size, the muscle size will also depend upon the amount of growth producing hormones genetically predisposed to each individual. Males who participate in a weight training program have the potential to increase muscle size to a greater extent than females in the same weight training program due to the male 
hormone, testosterone. Testosterone allows for significant increases in lean body tissue and skeletal growth (Baker, 1994). According to Baker, (1994), males have about ten times more testosterone than women and therefore have the potential to increase muscle mass more readily than most women; however, McArdle et al. (1991) claim that men have 20 to 30 times more testosterone than women, dramatically increasing their anabolic effect of muscle hypertrophy. In spite of this women continue to fear the increased muscle mass that results from a weight training program and as a result, women have avoided training with weights (Cinque, 1990). Not only do women not have sufficient testosterone to produce muscle mass growth similar to men, they also have a greater amount of the female hormone estrogen, which inhibits lean muscle tissue growth (Baker, 1994). Allowing for individual differences between women, some women have the potential to gain muscle mass more readily and with less effort, while others can gain noticeable increases in muscle mass by way of a weight training program. Other women may develop greater muscular strength without any noticeable increase in body size. A balanced exercise program will yield increased lean body tissue and decreased adipose tissue. Genetics largely dictate the results of an exercise program (McArdle et al., 1991), none of which would be known until a resistance training program has actually begun.

Muscular strength that occurs as a result of a resistance training exercise program is the result of physiological and neural adaptations. The neural adaptations include increased stimulation of the skeletal muscle, enhanced motor unit recruitment and synchronization, and improved coordination and learning (Rogers \& Evans, 1993). The physiological adaptations include muscle hypertrophy, increased strength, change in body composition, and changes in cardiovascular capacity (Rogers \& Evans, 1993). The increase in muscle strength increases lean muscle tissue which in turn maintains or 
increases the resting metabolic rate. Increases in resting metabolism aids in decreasing body fat and maintaining optimum body composition (Rogers \& Evans, 1993).

Additional adaptations to weight training are increased strength of the surrounding tendons and ligaments. Increasing muscle tendon and ligament sheath strength reduces the risks of injuries and improves one's ability to carry out daily tasks. Strength training has also been proven to increase bone density as well as muscle mass (McArdle et al., 1991; Rogers \& Evans, 1993). These two benefits are extremely crucial for a woman's health showing that strength training is of vital importance to women (Cinque, 1990).

Due to aging, the elderly suffer the effects of bone loss and lean muscle tissue loss greatly affecting their independence, mobility, and ability to carry out simple daily tasks. Bone density decreases gradually with age though it can be slowed by way of a resistance training program. A study conducted at Tufts University of the elderly (1994) showed that the elderly subjects were able to double their muscle strength and increase their physical activity by 35 percent. The increases enabled the subjects to walk faster and climb stairs with less effort. Regardless of age, Americans with an active lifestyle retain greater bone mass than their sedentary counterparts (McArdle et al., 1991). Resistance training and disease prevention

Research has claimed that weight training is highly recommended for the prevention of osteoporosis (McArdle et al., 1991; Marcus et al., 1992). According to Wardlaw, osteoporosis is a debilitating disease affecting 25 million Americans (Sharp, 1994). Of those affected by osteoporosis, most are thin, Caucasian, women (Sharp, 1994). Bone loss occurs in women after the age of 30-35 at the rate of 0.75 percent to 1 percent per year. At the onset of menopause this rate increases dramatically to 2 percent up to 3 percent per year. Osteoporosis is defined as decreased mineral mass leading to porous bones and an expanded medullary cavity (Tollison \& Kriegel, 1990). 
Osteoporosis is related to bone atrophy, decreased bone strength, increase in fractures and pain, and limited ambulation. The decrease in muscle mass greatly reduces resting metabolic rate. The muscle atrophy and weakness also lead to hip fractures, which often cause complications resulting in death (Rogers \& Evans, 1993; Tufts University Diet \& Nutrition Letter, 1994). Over 300,000 hip fractures will occur per year (McArdle et al., 1991; Tufts University, 1994), categorizing fractures as a greater risk for women than both breast and uterine cancer combined (Tufts University, 1994). One out of three women will suffer from a vertebral fracture (Tufts University, 1994). The collapse of the spine leads to poor posture, back pain, and breathing problems. Osteoporosis is eight times more common in women than in men (UCB Wellness Letter, July, 1993). For men, the rate of bone loss is as low as 0.4 percent per year starting after the age of 50 (Tollison \& Kriegel, 1990). Though men have 10-25\% more bone mass than women, one out of five men will fall victim to osteoporosis (Tufts University, 1994). As the lifespan increases for men this number will increase as well. Men are diagnosed predominantly in their 80's and 90's. Most diagnoses for women occur between the ages of 50 and 70. Unless some efforts are made towards prevention the number of diagnoses could double in 25 years (Tufts University, 1994). Bone density and muscular strength are known to be positively correlated (Tollison \& Kriegel, 1990).

Amenorrheic women can also be affected by osteoporosis. Evidence has shown that even young women can be affected by amenorrhea and are often overlooked as potential sufferers. A great percentage of young women who train intensely (i.e. marathoners, elite gymnasts, elite divers) can also suffer from amenorrhea. These women do not match the profile of typical osteoporosis patients. Bone loss in this group of women, usually athletes, may not be entirely reversible (Yeager, Agostini, Nattiv, \& Drinkwater, 1993). For all younger women, bone loss can be prevented with regular 
non-intense physical exercise (Tollison \& Kriegel, 1990).

Women also face menopause later in life. This change in the woman's body comes with many problems as well as many treatments. Menopause can be tolerated well if exercise is a part of a woman's daily routine (Dvorak, 1994). In addition to the physical strength a woman gains, exercise helps a woman's attitude and reduces the stress associated with menopause. Exercise may not eliminate all the symptoms associated with menopause, but it may help control weight gain, and give a woman a feeling of overall well being (Dvorak, 1994).

Menopause is itself a precursor to osteoporosis. The benefits of exercise on the prevention of this disease are immeasurable, as previously discussed. The high risk, postmenopausal women are severely disadvantaged due to estrogen deficiency. Although estrogen replacement therapy used during menopause is the greatest deterrent against osteoporosis, strength and aerobic training are also recommended not only for the prevention of, but also for, the treatment of osteoporosis (Cinque, 1990; Hargarten, 1994; Tollison \& Kriegel, 1990). McArdle et al., (1991) found that women without osteoporosis were stronger than women with osteoporosis. Once more, a link is found between bone density and muscular strength.

The benefits of resistance training in reducing coronary heart disease (CHD) are not well known, but weight training does effect some of the conditions related to CHD (Todd, 1991). Reduced muscle mass is implicated in the development of Type II diabetes, coronary artery disease, and hypertension, especially for the elderly (Rogers \& Evans, 1993). Weight training lowers cholesterol levels, lowers insulin levels after stimulation of glucose, and may lower blood pressure. The aforementioned benefits of weight training are helpful in preventing atherosclerosis which has shown a strong causeand-effect relationship with coronary heart disease (McArdle et al., 1991). Researchers 
at Tufts University (1994) also claim that strength training has the potential to improve the ratio of high density lipoproteins (HDL) cholesterol to low density lipoproteins (LDL) cholesterol. Weight training, however, should not be used as a means of improving cardiorespiratory fitness (ACSM, 1991). Hurley et al. (1988) found favorable results of plasma lipoprotein-lipid profiles without concurrent improvements in cardiovascular function. They discovered that high intensity resistance training improved cholesterol levels and decreased diastolic blood pressure with no change in $\mathrm{VO}_{2 \max }$, body weight or body composition. An earlier study by Hurley et al. (1984) uncovered similar results of high intensity resistance training. No improvements were found in cardiovascular function, nor changes in body weight or body fat, however muscular strength and free fat weight did increase.

Arthritic patients suffer from joint pain and are most often out of shape because rest was, in the past, the prescribed treatment. After studies have shown the benefits of aerobic exercise and strength training (Samples, 1990), exercise is now being used as one of the treatments for this disease. Because strength training also improves the strength of surrounding joints (McArdle et al., 1991; Cinque, 1990), it is very valuable for arthritis patients. Researchers at Tufts University (1994) also found similar effects claiming that strength training eases osteoarthritis pain and may even help the pain of rheumatoid arthritis. Structured programs are available and the level of participation is dependent upon the individual case (Samples, 1990).

The psychological benefits of weight training

Self-esteem is viewed as a very important aspect in understanding and defining human behavior. The aspiration to feel good about one's self is sought after by every human. Studies have shown a correlation between high self-esteem and a positive opinion of one's body. Conversely, a low opinion of one's physical self has also been 
correlated with feelings of self-doubt. Only a few studies have been conducted correlating self-ect=un and resistance training. Melnick and Mookerjee (1991) studied college students on a 16-week training program and found the subjects felt significantly better about themselves than the control group after the training program whereas, the pretest showed no differences between the two groups prior to training. Although the training group showed no significant difference in the level of self-esteem from the pretest to the post-test, the authors concluded that the program had a positive effect on the subjects' perceptions of their own attractiveness, self-worth, and physical condition (Melnick \& Mookerjee, 1991).

Cheryl Sacra, reporting in Shape magazine, (February, 1994) cautions against intense training. She reported that researchers from the University of Alabama, Birmingham had studied a group of competitive bodybuilders and discovered that instead of improved psychological benefits, they became more depressed, fatigued, and their self-image was drastically altered. However, the sample size was small, and the subjects were on a low caloric, restricted diet. Sacra also reported that Laura Newton, an exercise physiologist and nutritionist, also showed that heavy training and an extremely low calorie, low fat diet can cause or trigger mood swings. Newton's specific study was not cited in this article.

\section{Social aspects of weight training}

Misconceptions of weight training and muscle mass have existed for many years and have been passed on from one person to another. The aerobics "boom" has dominated the fitness industry for the last 10-20 years, shifting most of the focus of exercise on to cardiovascular training. Only recently has the fitness industry introduced any type of resistance training for muscle strengthening and toning. The initial aerobics "boom" made strength training seem less important and therefore many exercisers did 
not include strength training into their workout regimen (Kase, 1991). A renewed interest in weight training has emerged, but the emphasis is still not great enough to motivate and encourage people to participate in this activity as much as in cardiovascular conditioning. Not even in the full service health clubs can you find a predominance of strength training. The group exercise classes in these facilities, for example, are predominantly aerobic conditioning in nature. Few percentage of the classes offered involve muscle strengthening with the use of weights, or some other resistive type of equipment such as bands or tubing. Some group exercise classes will combine both cardiovascular conditioning and resistance training into classes with durations of 60 to 90 minutes. Although combining cardiovascular conditioning and resistance training is a good time management technique, the combination is not without limits. The amount of time spent on resistance training is limited, the intensity low to moderate. This may satisfy some individuals' needs. Other participants may need to do supplemental resistance training in order to achieve the intended goal of resistance training. The intensity should be moderate to high in order for the muscles to impart a physiological change.

Weight training bears false stereotypes and connotations. Women specifically have shied away from weight training because the predominant users have been bodybuilders and weight lifters. Even though it was once thought, and many still believe, that a participant would become muscle bound and lose flexibility by using weights, research has proven that to be a fallacy (McArdle et al., 1991). In spite of this research, both men and women still believe this fallacy to be true. Women particularly maintain the fear of "bulking up" (Cinque, 1990; Kosich, 1994). Influence of mass media

As technology evolves so does our ability to deliver information. Improvements 
in communication, visual, written, and auditory allow information to be dispersed quickly. Television, magazines, newspapers, books, and videos influence the publics' opinion on various topics, including health and fitness. The world wide web has also become a central information center for most of the world. The media delivers this information, censored or uncensored, to a public unarmed with tools to discern the truth.

Scanning any magazine shelf or checkout counter at the grocery store one finds themselves in the midst of "body beautiful" magazines. What becomes very apparent to the consumer is that a magazine would not be marketable if it did not make reference to getting some body part in shape or shedding some unwanted pounds. Headlines in the popular woman's Shape magazine such as " 4 Weeks to Fat Control", leads the reader to believe that not only is there a problem with body image, but that the article in the magazine can easily solve the problem. The media and advertisers will continue to barrage the reader with the "body ideal" pictures (Johnston, 1995). Unfortunately, there is no one way to achieve that perfect body, despite what the popular press wishes readers to believe; there is no perfect body, but there are safe guidelines and techniques for a healthy, fit body.

To further exacerbate the problem of the focus on the body beautiful, men and women with apparently beautiful and flawless bodies take center stage to most media presentations on television and in magazines. This phenomena also exists in exercise videotapes. It would be safe to conclude that the videotapes found on the shelves of popular video stores have pictures of the "body beautiful" on the cover and attract the consumer's attention. The fitness industry sits precariously in the middle of the cultural issues of body image (Johnston, 1995). These cover pictures usually represent the person leading the exercise on the videotape. Some exercise leaders use good taste and judgment in their cover pictures, and some do not, using their bodies inappropriately, 
either to induce feelings of sexual desire for that person or as a model to be like that person.

In Shape (Urbanska, 1994), a writer discussed the issue of body-image consciousness. Urbanska (1994), a writer for Shape magazine noted that women all across the world have been "manipulating" their bodies for centuries to suit and comply with society's expectations of what a body should look like. As women have become more educated and have assumed leading roles in the work force, the cultural ideal of body image has changed (UCB Wellness Letter, Dec., 1993). The phrase "you can't be too thin" is a dramatically stark representation of how women view themselves. Many women have come to believe that a particular body image (lean, mean, thin, strong) is the expectation and the norm (UCB Wellness Letter, Dec., 1993). This, of course, has led to an increasing rise in eating disorders, specifically, anorexia nervosa and bulimia.

Urbanska (1994) claimed that it was not until the 1970's that the medical community made the connection between distorted body image views and eating disorders. Urbanska continued to report that body-image distortion has reached epidemic proportions. In Urbanska's article, Maria Baldwin stated that most women, regardless of age or genetic disposition felt the need to attain a perfect body. Joni Johnson, psychologist and author, stated it is normal to have a negative reaction to one's body because of the pictures and models seen on television. Poor body image gives rise to negative language about one's body, overexercising, and undereating (Johnston, 1995). Eating disorders, linked with the drive to be thin have cut across socioeconomic class, age, and gender lines.

Body image consciousness is not for women only. Men also have negative images of their bodies. Durrett (1995), cited a group of psychologists that revealed men are beginning to "loathe" their bodies and becoming addicted to exercise. Gavin (as 
cited in Durrett, 1995), claimed this trend is due, in large part, to the increased number of women in the leadership position in the workplace.

On the other hand, the media has represented itself well. Research information is making its way into the popular press articles. Research has stated that muscle tissue is a metabolically active tissue; it burns calories while at rest. Fat tissue is not metabolically active and does not bum calories at rest. Therefore, the greater one's ratio of muscle tissue to fat tissue the higher one's metabolism (Kravitz, 1994). Kase (1991) reporting in the popular press stated similar information. Quite frequently popular press articles present research based information through consultation with experts in the field of exercise physiology. Experts have also been consulted in the production and design of exercise videotapes. Most movie stars and television celebrities do not have the knowledge or technical skills to produce a weight training exercise videotape. However, some enthusiastic actors, actresses, models, and even professional athletes are making and marketing videotapes without the use of experts, which calls into question the reliability of the information, safety of procedures, and exercises being presented.

\section{$\underline{\text { Summary }}$}

The exercising population is still very small considering the tremendous benefits of exercise. The apparent need to encourage Americans to participate in exercise is demonstrated by the startling figures that almost 80 percent of the population is still inactive. Infinite opportunities exist from which to choose to involve oneself in an active lifestyle and evolve into an active individual. One of these opportunities is through popular home exercise videotapes.

The media has become an essential, powerful, and influential medium and source of information in today's society. Exercise videotapes developed by well known people have therefore become very popular. The need subsequently arises to assess these 
videotapes to determine their appropriateness and effectiveness for those who partake in this form of activity. 


\section{CHAPTER III}

\section{METHODS}

\section{Introduction}

The purpose of this section is to describe the procedures and methods that were used to evaluate the exercise videotapes. The methodology includes the videotape selection process and a description of the instrument used for videotape evaluation. The data collection process and the data analysis are also outlined.

\section{Selection of videotapes}

The original proposal required that ten videotapes be reviewed for the study, five from those whose status was described as a "celebrity" and five from those whose status was described as a fitness expert. However, because only three fitness expert exercise videotapes met the selection criteria, five celebrity and three fitness expert exercise videotapes were reviewed. The celebrities whose videotapes were chosen for use in this study did not have any specific criteria to meet other than being recognized as a celebrity. The celebrities also did not have to have any experience in the fitness industry nor have published a previous exercise videotape. The fitness experts' videotapes were selected on the basis that their teaching experience spanned more than two years and they must have made at least one videotape prior to the videotape evaluated in this study. The fitness experts were experts in the field of exercise, exercise instruction, and/or are exercise leaders.

In order to be selected for review all eight videotapes met the following criteria: 1) the videotape must have stated on the label that it is a full body workout inclusively: 2) the videotape may have contained aerobic dance, step aerobics, or any other type of movement with the intent of producing cardiovascular conditioning however, only the portion of the videotape that included resistance training was evaluated. The instructors 
could use props including but not limited to dynabands, Sprim tubing, hand held weights, or step benches. The props may not have in any way be used to induce cardiovascular conditioning during the muscle conditioning phase being evaluated.

All videotapes available at popular major video stores that met the criteria previously mentioned were selected for the pool from which a random sample of videotapes were selected. If a videotape met the criteria a determination was made as to whether the videotape was led by a celebrity or a fitness expert. Each videotape was listed and numbered in two columns, one column for celebrity titles, the second for trained exercise fitness expert titles. Five numbers were randomly selected from the celebrity title column and all three fitness expert videotapes available from the fitness expert title column were evaluated. The eight videotapes were chosen from popular major video stores such as Hollywood Video, Virgin Records, The Wherehouse, Blockbuster Video, and Tower Records. These commercial venues were chosen because they represented the video stores available to the general public in a large metropolitan area.

\section{Instrumentation}

The Likert-scale rating instrument used for evaluation of each videotape was developed by the researcher based on current ACSM standards and guidelines for implementing an exercise class. The instrument assessed each training component of the exercise routine using a rating scale ranging from poor, fair, and good, to excellent, with points given to each from one to four, respectively. The instrument, titled Video Critique can be found in Appendix A. The Video Critique was divided into two main phases, the Warm-up and Exercise phases. Each phase was further delineated to evaluate specific aspects and training components presented on the videotape and of the instructor. 
The first phase of the Video Critique, the Warm-up, was divided into three sections, the active section, the stretch section, and the overall presentation. The warmup is an integral part of any exercise routine by increasing blood flow and raising the muscle and the core temperature by gradually preparing the body for the upcoming activities using full range of motion of the joints (McArdle et al., 1991). The active section of the Warm-up phase evaluated the execution, alignment, range of motion, and choice of moves of any active movement during the warm-up phase. The stretch section determined if the major muscles of the upper and lower body were stretched and examined the execution of the stretch. The overall presentation section evaluated the cueing, voice, music selection, appearance and enthusiasm of the instructor.

The second phase of the Video Critique the Exercise Phase, evaluated the exercises used for strength or endurance training for each muscle group. This phase was divided into four sections, the exercise section. the cooldown/stretch, overall exercise selection, and overall presentation.

During the exercise section, the exercises were evaluated in the order in which they appeared. According to Kravitz (1992), muscle groups should be concentrically contracted in a prescribed order. He recommends the order to be from large to small muscle groups so as not to fatigue the smaller ones. The suggested order is from legs, to upper torso, to the arms and abdominals. Each exercise demonstrated by the instructor was evaluated based on the instructor's form, alignment, and ability to teach the exercise. To reduce inflation of the scores due to the number of exercises each instructor chooses to include, but yet allow representation of choices to be included in the data analysis, a mean rating was calculated for the number of exercises performed. Any equipment selected to perform the exercise was noted by the investigator. The Video Critique allowed the researcher to note the muscle group being exercised as well as the exercises 
being chosen for that particular muscle group.

The next section of the Exercise Phase, the cooldown/stretch, asked yes or no questions of the post-stretch. This section also determined if all the major muscles were exercised during the exercise portion of the videotape. Furthermore, this section determined whether a stretch was completed for each muscle that was exercised, the amount of time each stretch was held, if breathing and relaxation were encouraged, and whether the stretches were appropriate. Stretching and relaxing are an integral part an overall balanced fitness program (Pilgrim, 1995). Static stretching is the most effective tool in bringing about flexibility and is important to daily living tasks, (ACSM, 1991), as well as injury prevention and alleviation of muscle soreness (Colorado, 1994). Because stretches should be held for 10 to 60 seconds to be effective, the average time held being 15 to 30 seconds, (Colorado, 1994; ACSM, 1991), the Video Critique chose 15 seconds as the determination of a sufficient stretch. While stretching, breathing and relaxing can be used as a tool to slow the brain, bringing about a decrease in heart rate.

The next section of the Exercise Phase, the overall exercise selection, asked yes or no questions, to evaluate the appropriateness of the exercises that were chosen and whether a variety of exercises were offered for each muscle group. The last section of the Exercise phase, the overall presentation, evaluated choreography, music selection, and the instructor's explanation of the muscles being worked and his/her ability to explain the exercises in easy-to-understand terms. This section also determined production quality of the videotape and the motivational skills of the instructor. A Comments Section allowed the researcher to make notes of items in the videotape that may not be represented on the Video Critique. Interobserver agreement of Video Critique

The Video Critique was evaluated prior to data collection to ensure that the 
information collected using the instrument could accurately assess the exercise videotapes, given the purpose of the study. To accomplish this the researcher reviewed a randomly selected videotape, one that was not chosen in the final selection of videotapes analyzed, using the Video Critique instrument. The videotape chosen was a celebrity videotape. The same videotape was reviewed using the Video Critique by an independent observer with experience and/or expertise in the field of physical education. This person has studied physical education, (certified by any of the three certification agencies listed previously), and has at least one year of experience as a certified group exercise instructor. The two independent reviews of the same videotape were compared to determine interobserver agreement of the instrument. The following formula was used to determine whether the Video Critique was a reliable instrument:

$$
\text { I.O.A. }=\frac{\text { Agreements }}{\text { Agreements }+ \text { Disagreements }} \times 100
$$

This procedure determined that the Video Critique was a reliable tool for the evaluation of the videotape with an IOA of $92 \%$. Where disagreements arose, adjustments to the Video Critique were incorporated into the final instrument used to collect data. Data collection was completed by the researcher.

\section{Data collection}

The videotapes were evaluated using a Likert scale that ranged from 1- 4 signifying a poor, fair, good, or excellent rating, respectively. An "excellent" rating was given if the instructor made no more than one critical error in the section evaluated. A "good" rating was given when two critical errors were made. A rating of "fair" was given when three errors were made. A "poor" rating was issued when four or more errors were made in the section that was being evaluated. Errors included actions that are considered contraindicated, such as unsupported forward flexion, hyperextension or hyperflexion, or 
movements that put undue stress on the lower back or knees. Errors also included movements that the instructor demonstrated with flaw such as, violating body alignment, incorrect execution of an exercise, poor form, or inaccurately describing and/or demonstrating an exercise.

Several sections of the Video Critique required the researcher to rate the presence or absence of a training component using a YES or NO. A "YES" rating received one point. A "NO" rating received zero. The total points were calculated for each exercise videotape. The exercise videotapes were ranked in numerical order from one to eight, highest to lowest, based on their total points scored. After a rank order was made, the top four videotapes were reviewed and summarized to determine the essential training components from each of the four videotapes that contributed to its excellence. This process included a comparison of each of the four videotapes' critique to determine the similarities among the four videotapes. This summary provided the researcher the information necessary to render recommendations for future exercise videotape development. Recommendations were made as to the criteria required for an exercise videotape to be considered good or excellent, safe, and effective for the general public's use. Recommendations also included what type of instructor the public should look for when choosing an exercise videotape, and how to choose the right exercise videotape for one's own specific needs. 


\section{CHAPTER IV \\ RESULTS AND DISCUSSION}

This chapter focuses on the data analysis and results of the major training components delineated in the Video Critique with regard to usefulness, accuracy, and safety. The training components, the Warm-up phase and its three sections, the active section, stretch section, and overall presentation section, along with the Exercise phase and its four sections, the exercise section, cooldown/stretch section, exercise selection section, and overall presentation section, were evaluated using the Video Critique. The results and discussion are based on the analysis of five celebrity videotapes and three fitness expert videotapes. For each training component of the exercise videotapes the results will be presented for the celebrity group and the fitness expert group separately. Observational insights for each videotape as seen by the researcher and recorded in the general comments section of the evaluation instrument will subsequently be discussed.

The initial intent of this study was to evaluate a total of ten videotapes, five randomly selected exercise videotapes produced with celebrities and five exercise videotapes produced with fitness experts. The total number of videotapes that were available for the random sample of celebrities was thirty-eight. The total number of fitness expert videotapes that were available for the random sample however, was only two.

Due to the lack of fitness expert videotapes the total number of videotapes evaluated had to be reduced to eight. Six of these videotapes used a celebrity name in the title and two used a fitness expert name in the title. However, one celebrity videotape was actually taught by a fitness expert. The celebrity did appear in the videotape alongside the fitness expert performing the activities as instructed by the fitness expert. 
In this case, the videotape was evaluated in the fitness expert category. Therefore, a total of three fitness expert videotapes and five celebrity videotapes were reviewed and evaluated.

The evaluation of each videotape provided a total points scored. The top ranked videotape will be discussed in order to describe the qualities and attributes that led to its success. In addition, recommendations were made as to the features necessary for the prediction of a useful, accurate and safe exercise videotape.

Since the researcher evaluated and recorded the data an interobserver reliability quotient was calculated to ensure the accuracy of the data. A trained fitness expert, certified by one of the three organizations meeting the criteria for the fitness expert status in this study, was used to check the accuracy of the data. Both the researcher and the observer independently critiqued the same videotape using the Video Critique instrument. It was found that the interobserver rater agreed with the researcher $92 \%$ of the time. This percentage indicates that the researcher used the Video Critique instrument accurately and reliably. The Video Critique can be found in Appendix A. Data Analysis

Using the Video Critique instrument, data showed that during the introduction of the videotape, $100 \%$ of the celebrities gave a description of the format of the workout, a description of the equipment that would be necessary to participate in the workout, and recommendations for adapting exercises for different levels of exercisers. Only $40 \%$ of the celebrities introduced themselves during the introduction of the videotape.

All the fitness experts gave a full description of the workout, a description of the equipment necessary to perform the exercises, and recommendations for adapting exercises for different levels of participants. Of the fitness experts, only $33 \%$ introduced themselves during the introduction of the videotape. 


\section{Warm-up - Active Phase}

The mean times allocated to each training component of the exercise program can be found in Table 1 . The mean total warm-up time, including both the active and the stretch phase of the warm-up, for all the celebrities was 5 minutes 12 seconds. The celebrity group had a mean time of 3 minutes 12 seconds for the active phase and 2 minutes 0 seconds for the stretch phase. Celebrity $\# 1(\mathrm{Cl})$ had the longest warm-up time, a total of 8 minutes, 4 minutes for the active phase and 4 additional minutes for the stretch phase. Celebrity \#2's (C2) total warm-up time was 7 minutes, 3 minutes 45 seconds for the active phase and 3 minutes 15 seconds for the stretch phase. Celebrity \#3's (C3) total warm-up time was 2 minutes, all for the active phase. There was no stretch phase in C3's warm-up. Celebrity \#4 (C4) had a total warm-up time of 5 minutes; 2 minutes for the active phase and 3 minutes for the stretch phase. Celebrity \#5 (C5) had a total warm-up time of 4 minutes, all for the active phase. C5 had no stretch phase in the warm-up.

The mean total warm-up time, including both the active and the stretch phase of the warm-up, for all the fitness experts was 4 minutes 18 seconds. The fitness expert group had a mean time of 3 minutes 36 seconds for the active phase and 36 seconds total for the stretch phase. Fitness expert \#1 (FEI) had a total warm-up time of 4 minutes; 2 minutes for the active phase and 2 additional minutes for the stretch phase. Fitness expert \#2 (FE2) had a total warm-up time of 4 minutes, all for the active phase. There was no stretch phase in FE2's warm-up. Fitness expert \#3 (FE3) had a total warm-up time of 5 minutes, all for the active phase. FE3 also had no stretch phase. This information is striking since lightly stretching muscles after a general warm-up has been shown to be necessary for safety and injury prevention (ACSM, 1991), in addition to preparing the body for the workout (McArdle et al., 1991). The fitness expert group 
Table 1

Mean Time in Minutes and Seconds for The Warm-up, Exercise, and Stretch Phases for the Celebrity and Fitness Expert Groups

Celebrities

$$
n=5
$$

$3: 120$

2:00.0

$16: 12.0$

$5: 48.0$
Fitness Expert

$$
\mathbf{n}=3
$$

$3: 40.0$

$0: 40.0$

20:18.0

Mean cooldown/stretch phase time

Note: Time is in minutes and seconds. 
failed to deliver a minimum stretch prior to the workout. Compared to the celebrities, where four out of five included a stretch phase in their warm-up, only one out of three fitness experts included a stretch phase in their warm-up.

The Video Critique also allowed observation of eight additional variables of the instructors' active phase of the warm-up. These variables included clean and sharp movements, clear demonstration of the desired action, transitions between movements, alignment, both spinal and hip to ankle alignment, and range of motion (ROM). The Video Critique also allowed identification of the choice of moves (refer to Video Critique in Appendix A) to determine if the exercises were appropriate for the intended audience and met the design of the workout. A rating was calculated for each variable for all the instructors. The variables were rated on a scale from one to four, one being the lowest and four the highest possible rating signifying a poor, fair, good, or excellent rating, respectively. An "excellent" rating was given if the instructor made no more than one critical error in the section evaluated. A "good" rating was given when two critical errors were made. A rating of "fair" was given when three errors were made. A "poor" rating was issued when four or more errors were made in the section that was being evaluated.

Figure 1 displays the mean ratings for both groups for each variable. The celebrity group received mean ratings of $\mathbf{2 . 7}$ for demonstrating clean and sharp movements, 3.8 for clear demonstration of the desired action, and 3.4 for transitions between exercises. The celebrity group received mean ratings of 3.2 for appropriate spinal alignment, 2.4 for hip to ankle alignment, and 3.2 for ROM. The celebrity group received a mean rating of 3.0 for choosing moves appropriate for the intended audience and 2.4 for the warm-up meeting the design of the workout. $\mathrm{Cl}$ 's mean rating of all eight variables was 3.12. C2's mean rating of all eight variables was 3.20. C3's mean rating 


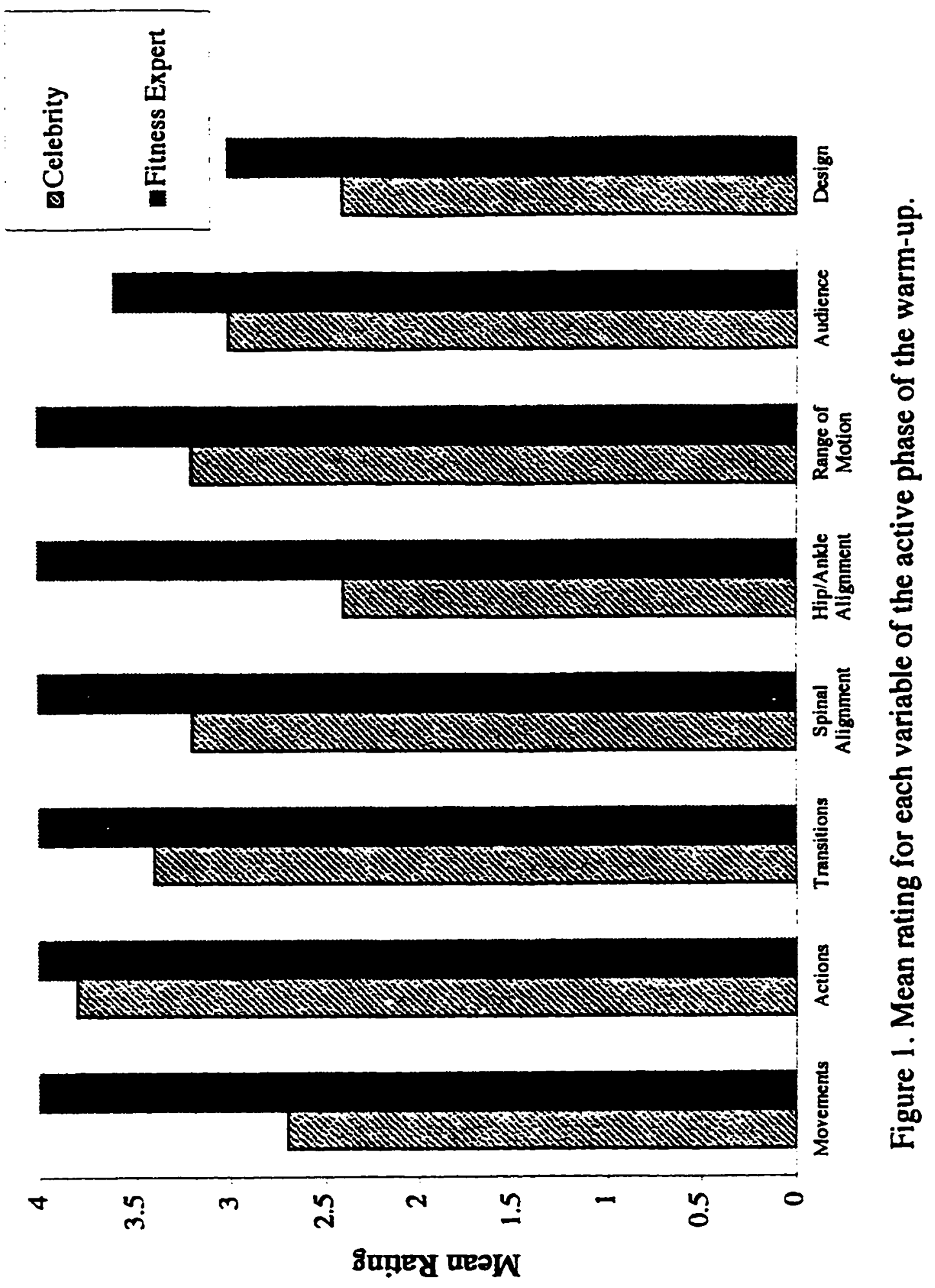


of all eight variables was 2.24. C4's mean rating of all eight variables was $3.36 . \mathrm{C}^{\circ} \mathrm{s}$ mean rating of all eight variables was 3.0.

Out of the possible four points available on the rating scale, the fitness expert group received mean ratings of 4.0 for executing clean and sharp movements, clearly demonstrating the desired action, and demonstrating smooth transitions between exercises. The fitness expert group also received a mean rating of 4.0 for spinal alignment, hip to ankle alignment, and ROM. The fitness experts were slightly better at determining appropriate exercises for the intended audience and received a mean rating of 3.6. In addition, the fitness expert group had a mean rating of 3.0 for meeting the design of the workout. FEl's mean rating of all eight variables was 4.0. FE2's mean rating of all eight variables was 3.76. FE3's mean rating of all eight variables was also 3.76. These results clearly show that the fitness experts were much more skilled at demonstrating accurate exercise movements.

Warm-up - Stretch Phase

The Video Critique allowed the researcher to assess the inclusion of stretches of predetermined muscles and evaluate the quality of execution of the stretch by each instructor. These seven predetermined muscles included the hip flexor/quadriceps, hamstrings, shoulders, upper and lower back, chest, and calves. These major muscles are considered important to include in a total body workout and should be prepared in order to complete subsequent exercises (Colorado, 1994). The execution of these stretches was rated based on the criteria previously mentioned. The maximum possible points for performing all the stretches was seven, one point for each muscle group. Additionally, the execution of each of the seven stretches was rated on a scale of one to four, with one being the lowest and four the highest rating possible. A maximum of 28 points was available for the rating of the stretches, a maximum number of seven stretches rated a 
maximum of four points each. The rating was based on alignment, form, and cueing for each stretch performed. The mean value for the execution of the stretches was calculated.

Some of the instructors performed their stretches actively, that is, the stretches were included in the active phase of the warm-up, done rhythmically. If this condition occurred, the stretch was evaluated as part of the stretch phase and not evaluated in the active phase described previously. Table 2 represents the mean and individual ratings of the stretches performed by the celebrities and fitness experts. The celebrity group performed a mean of 4.6 out of seven, or $71 \%$, of the predetermined stretches. The celebrity group's mean rating for the execution of the stretches was 2.67 .

$\mathrm{Cl}$ performed five out of the seven stretches including the shoulders, upper and lower back, hip flexor, and calves, with a rating of 3.2 for execution. C2 performed six out of the seven stretches including the shoulders, upper and lower back, hip flexor, chest and calves, with a rating of 2.67 for execution. C3 performed four out of the seven stretches including the shoulders, upper and lower back, and hip flexor, with a rating of 2.0 for execution. $\mathrm{C} 4$ performed six out of the seven stretches including the shoulders, upper and lower back, hip flexor, hamstrings, and calves, in the warm-up with a rating of 3.16 for execution. C5 performed three out of the seven stretches including the shoulders, hip flexor, and calves, with a rating of 2.33 .

The fitness experts performed a mean of 4.3 out of 7 , or $61 \%$, of the predetermined stretches during the stretch phase. The fitness expert group's mean rating for the execution of the stretches was 4.0. FEl performed all seven of the stretches including the shoulders, upper and lower back, hip flexor, hamstrings, calves, and chest, with an execution rating of 4.0. FE2 performed only two out of the seven stretches including the shoulders and upper back, with an execution rating of 4.0. FE3 performed 
Table 2

Mean and individual presentation of the number of stretches performed and execution rating of the celebrity and fitness expert group in the warm-up phase

No. of stretches performed

Execution rating

\begin{tabular}{lll} 
Celebrity 1 & 5 & 3.2 \\
Celebrity 2 & 6 & 2.67 \\
Celebrity 3 & 4 & 2.0 \\
Celebrity 4 & 6 & 3.16 \\
Celebrity 5 & 3 & 2.33 \\
Celeb/Mean & 4.6 & 2.67 \\
\hline & & \\
Fitness Expert 1 & 7 & 4.0 \\
Fitness Expert 2 & 2 & 4.0 \\
Fitness Expert 3 & 4 & 4.0 \\
Fitness Ex/Mean & 4.3 & 4.0 \\
\hline
\end{tabular}


four out of the seven stretches including the shoulders, upper back, hip flexor, and chest, with an execution rating of 4.0 . These results showed that the fitness experts demonstrate accuracy in the stretching exercises. The results also show, however, that the fitness experts neglected to perform almost $40 \%$ of the predetermined stretches. The fitness experts spent less time on stretching, preparing the muscles for the exercises, and more time on the resistance training exercises. However, fitness expert \# I who performed all the stretches of the Video Critique did not do a resistance training exercise for all muscles stretched. Conversely, fitness experts \#2 and \#3 did the opposite. They performed one or more exercises for all the predetermined muscles in the stretch phase of the Video Critique however, failed to include a warm-up stretch for all the muscles.

\section{Overall Presentation}

The Video Critique allowed the researcher to analyze the overall cueing and voice, including tone and enunciation for each instructor. In addition, the instructors were evaluated on music selection, appearance, including choice of attire and physique, and enthusiasm. Camera angles for the entire warm-up, both the active and the stretch phases were also analyzed. These eight variables were rated on a scale from one to four, a rating of one being the lowest and four the highest possible rating. The mean for each variable was calculated for the celebrity group and the fitness expert group.

Additionally, a calculation was determined for each instructor as to their accuracy of executing all eight variables.

Figure 2 graphically represents the mean rating for the fitness expert and celebrity groups for each of the eight variables included in the overall presentation of the warm-up. The celebrity group had a mean rating of 2.2 for cueing, 2.6 for tone, and 3.2 for enunciation. The celebrity group had a mean rating of 3.4 for choice of attire and 3.8 for physique. Their mean rating for enthusiasm was 3.4, 3.0 for music selection, and 3.0 for 

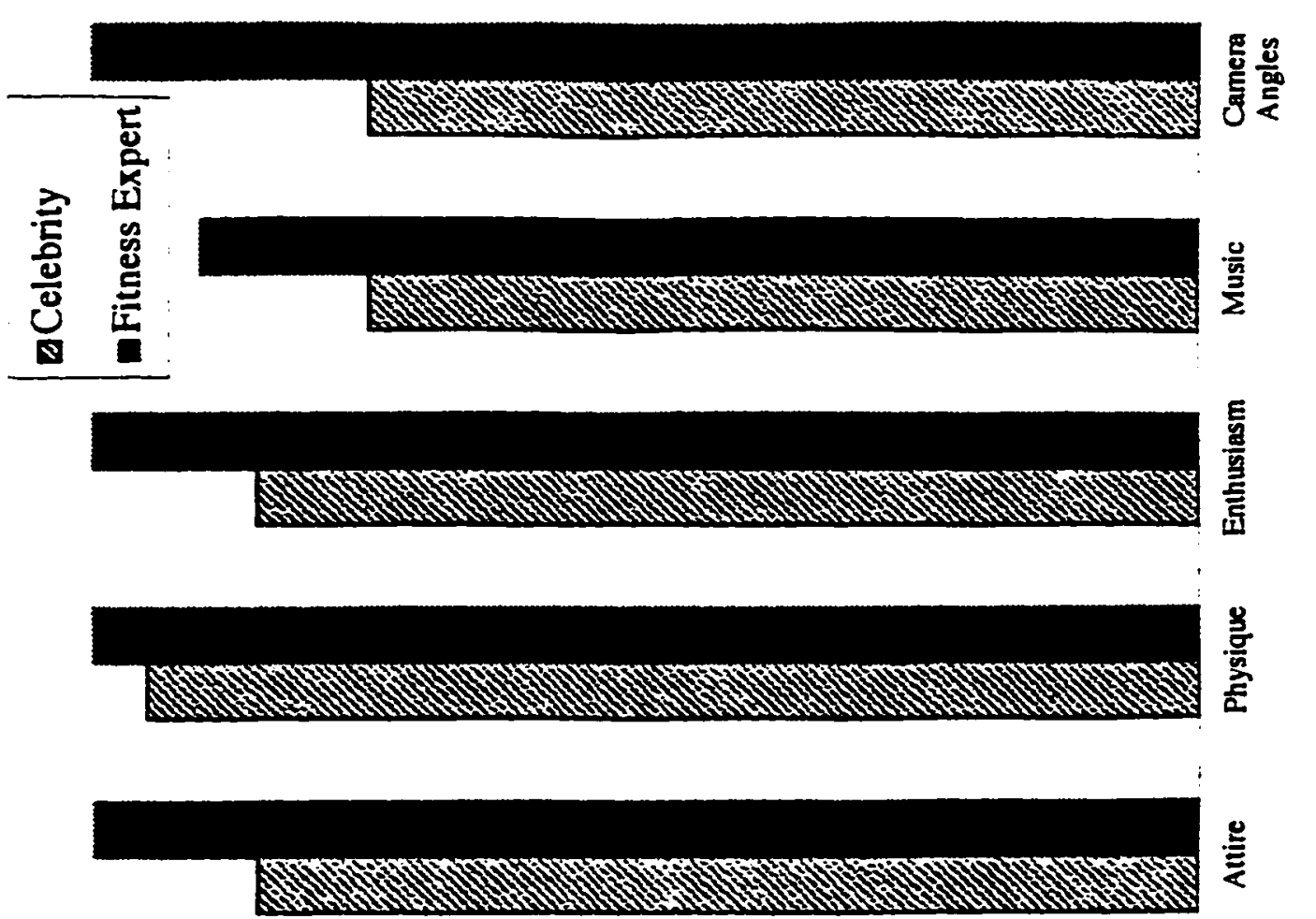

.

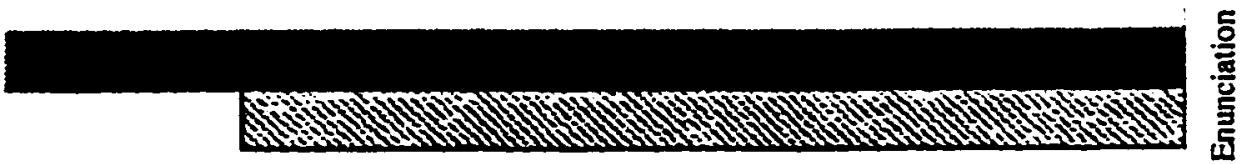

$\overline{\bar{\sigma}}$

20

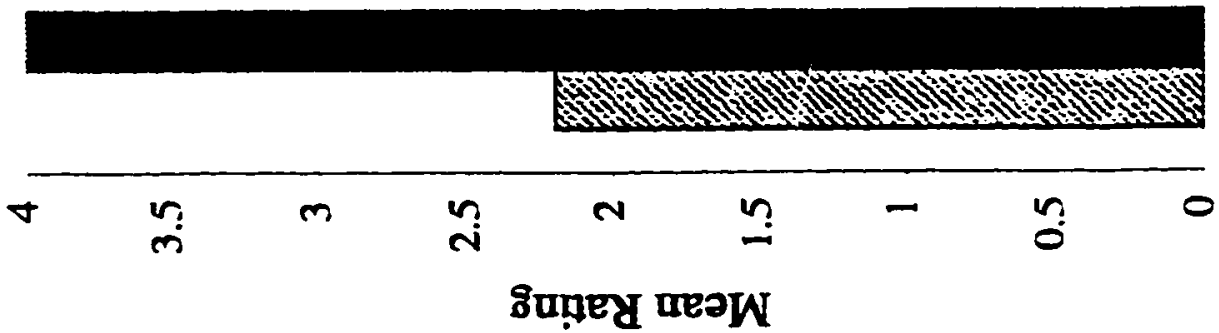

茨 
camera angles choices.

The fitness expert group had a mean rating of 4.0 for cueing, 3.6 for tone and 4.0 for enunciation. The fitness expert group received a mean rating of 4.0 for attire and 4.0 for physique. Their mean rating for music selection was $3.6,4.0$ for enthusiasm, and 4.0 for camera angle choices.

These ratings clearly indicate that the fitness experts execute their moves in a much more fluid manner compared to the celebrities. Observing their routine was pleasing to the eye. The fitness experts' ability to explain the desired movements well made the instructor easy to follow. This quality could contribute to feelings of success for the participants, an important ingredient for exercise adherence. In addition, the fitness experts gave excellent cues for the exercises during the workout, clearly enunciating their words and phrases. Their choice of music was motivating as were the fitness experts themselves. The fitness experts also chose appropriate camera angles with which to demonstrate and explain the movements, exercises, and actions desired for the participant/viewer. This may contribute to the participant remaining focused, not getting distracted by suggested or unnecessary behaviors, therefore enabling the participant to follow the instructor more easily.

\section{Exercise Phase}

During the exercise phase the researcher evaluated all the exercises chosen and performed by the instructors using the Video Critique. The exercises that were evaluated were only those involving resistance training. Each exercise was evaluated on alignment, form, and cueing. The rating for each of these elements was based on a scale from one to four, one being the lowest and four the highest possible rating. The length of time of the exercise phase, as well as the number of exercises shown, was also noted. Table 3 summarizes the results of the exercise phase. The celebrity group's mean time for the 
Table 3

Number and Length of Exercises and Mean Rating for the Celebrity and Fitness Expert Groups for Components Evaluated During the Exercise Phase

\begin{tabular}{lccccc}
\hline & No. of exercises & Length of time & Alignment & Form & Cueing \\
\hline $\mathrm{Cl}$ & 15.0 & $17: 00.0$ & 3.73 & 3.60 & 3.86 \\
$\mathrm{C} 2$ & 12.0 & $13: 00.0$ & 2.08 & 2.08 & 1.92 \\
$\mathrm{C} 3$ & 25.0 & $37: 00.0$ & 2.75 & 3.08 & 3.33 \\
$\mathrm{C} 4$ & 15.0 & $12: 00.0$ & 3.13 & 3.13 & 2.40 \\
$\mathrm{C} 5$ & 12.0 & $20: 00.0$ & 2.91 & 2.60 & 2.58 \\
All & 15.8 & $16: 12.0$ & 2.92 & 2.89 & 2.81 \\
\hline & & & & & \\
FE1 & 9.0 & $9: 00.0$ & 3.66 & 3.44 & 3.33 \\
FE2 & 20.0 & $25: 00.0$ & 3.95 & 3.95 & 3.80 \\
FE3 & 25.0 & $27: 00.0$ & 4.0 & 4.0 & 3.96 \\
All & 18.0 & $20: 18.0$ & 3.87 & 3.79 & 3.69 \\
\hline
\end{tabular}

Note: $C$ is for Celebrity, FE is for Fitness Expert; time is in minutes and seconds. 
exercise phase was 16 minutes 12 seconds. The celebrity group performed a mean of 15.8 exercises during the exercise phase. The celebrity group received a mean of 2.92 for their alignment skills, 2.89 for their form, and 2.81 for their cueing ability.

$\mathrm{Cl}$ 's total exercise time was 17 minutes and $\mathrm{Cl}$ performed 15 different exercises during that time. The mean rating for all 15 exercises for $\mathrm{C} 1$ was 3.73 for execution of alignment. $\mathrm{Cl}$ obtained a mean rating of 3.60 on proper form and 3.86 for accurately cueing the exercises of the workout. C2's total exercise time was 13 minutes and C2 performed 12 different exercises during that time. C2's mean rating for all 12 exercises was 2.08 for execution of alignment, 2.08 for proper form, and 1.92 for cueing the exercises of the workout correctly. Although C3's total exercise time was 37 minutes the workout was divided into two separate sections. C3 performed 25 different exercises in 37 minutes. C3's mean rating of all 25 exercises was 2.75 for execution of alignment, 3.08 for proper form, and 3.33 for cueing the exercises of the workout correctly. C4's total exercise time was 12 minutes during which time 15 different exercises were demonstrated. C4's mean rating of all 15 exercises was 3.13 for execution of alignment, 3.13 for proper form, and 2.40 for cueing the exercises of the workout correctly. C5 performed 12 different exercises in 20 minutes. C5's mean rating of all 12 exercises was 2.91 for execution of alignment, 2.60 for proper form, and 2.58 for correctly cueing the exercises of the workout.

The fitness expert group had a mean time of 20 minutes 18 seconds for the exercise phase. The fitness experts performed an average of 18 exercises during the exercise phase. The fitness experts received a mean of 3.87 for alignment, 3.79 for form, and 3.69 for cueing ability.

FEl's total exercise time was nine minutes where an equal number of nine different exercises were performed. FEl's mean rating of all nine exercises performed 
was 3.66 for execution of alignment, 3.44 for proper form, and 3.33 for correctly cueing the exercises of the workout. FE2 performed 20 different exercises in a total exercise time of 25 minutes. FE2's mean rating of all 20 exercises was 3.95 for execution of alignment, 3.95 for proper form, and 3.80 for correctly cueing the exercises. FE3's total exercise time was 27 minutes in which 25 different exercises were demonstrated. FE3's mean rating of all 25 exercises was 4.0 for execution of alignment, 4.0 for proper form, and 3.96 for correctly cueing the exercises of the workout.

\section{Cooldown/stretch phase}

The cooldown and stretch phase of the Video Critique focused on six specific questions. The questions focused on whether a resistance exercise was shown for all the major muscles and if the instructor included a stretch for that specific muscle. The major muscles in question were the muscles of the lower body, buttocks, thighs, and calves, and the muscles of the upper body, the chest, back, shoulders, triceps, biceps, and abdominals, (Kravitz, 1992). The remaining four questions in the Video Critique asked whether the stretches were held for at least 15 seconds, if the instructor encouraged breathing and relaxing during the stretch phase, and if the stretches were appropriate for the intended audience. The length of the cooldown/stretch phase was also recorded.

The average time for the celebrity group's stretch phase was 5 minutes 48 seconds (see Table 1). Table 4 displays the results of the celebrity and fitness expert groups stretching criteria. The celebrity group successfully achieved positive responses to 3.6 out of the six questions asked on the Video Critique for the stretching phase. $\mathrm{Cl}$ 's total cooldown time was six minutes. $\mathrm{Cl}$ achieved positive responses to five out of the six questions successfully. $\mathrm{Cl}$ exercised all the major muscle groups and performed a stretch for all the muscles exercised during the workout. $\mathrm{Cl}$ encouraged breathing, relaxing, and chose appropriate stretches for the intended audience. $\mathrm{Cl}$ did not hold the 


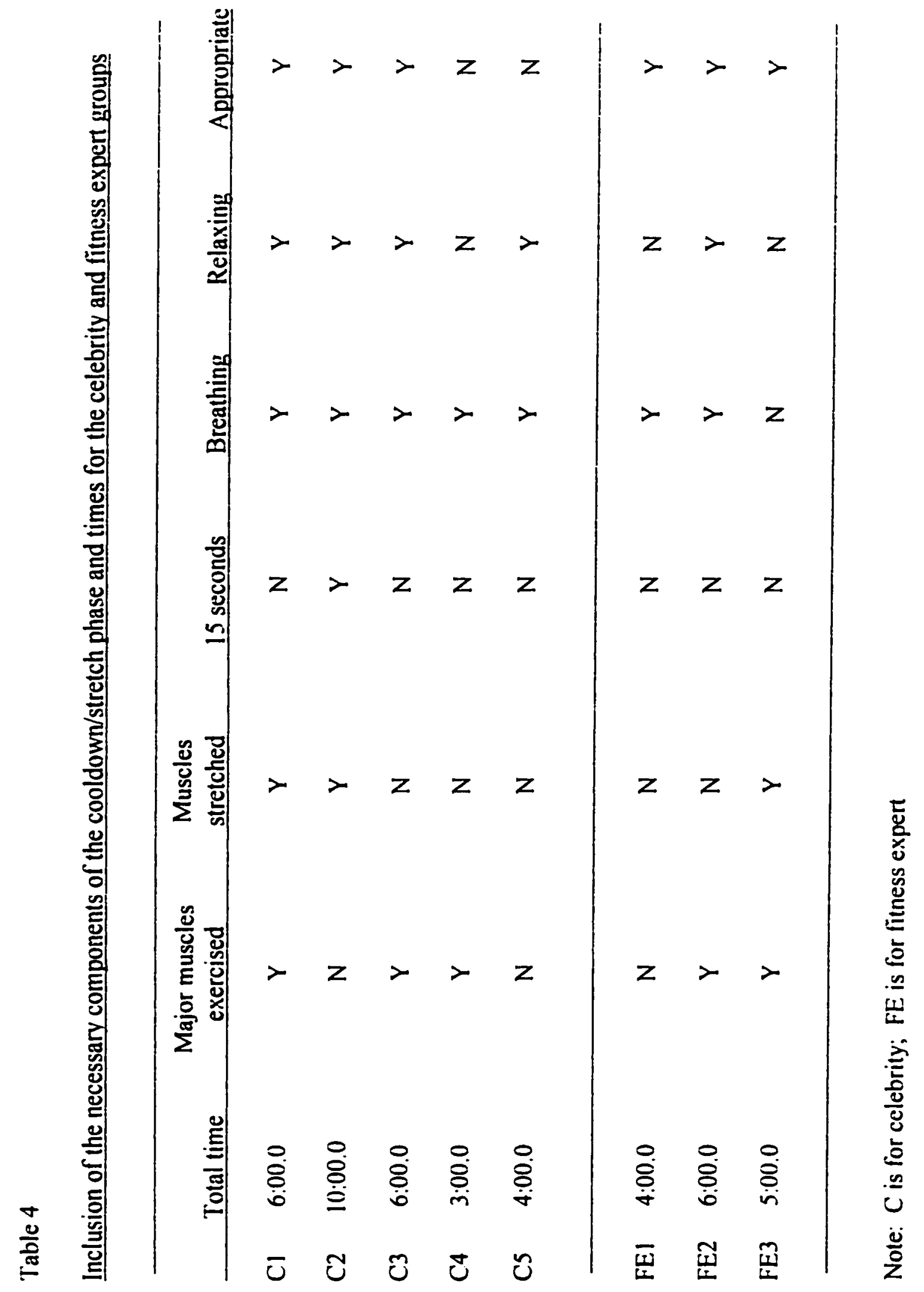


stretches for at least 15 seconds. C2's total cooldown time was 10 minutes. C2 achieved positive responses to five out the six questions on the Video Critique. C2 did not exercise all the major muscle groups and excluding the bicep muscle however, did perform a stretch for the muscles that were exercised during the workout and held the stretches for at least 15 seconds. $\mathrm{C} 2$ encouraged both breathing and relaxing during the stretches, and chose appropriate stretches. C3's total cooldown time was six minutes. C3 achieved positive responses to four out the six questions successfully. C3 accomplished this by demonstrating exercises for all the major muscle groups however, did not stretch all the muscle groups during the workout. C3 did not hold all the stretches for 15 seconds, but did encourage both breathing and relaxing during the stretch, and chose appropriate stretches. C4's total cooldown time was three minutes and only achieved positive responses to two out of the six questions on the Video Critique. C4 exercised all the major muscle groups however, did not perform a stretch for all the muscles exercised. C4 encouraged breathing during the stretch but did not encourage relaxing, nor held the stretches for at least 15 seconds. In addition, not all the stretches were appropriate for the intended audience. C5's total cooldown time was four minutes. C5 achieved positive responses to two out of the six questions on the Video Critique. C5 did not exercise all the major muscle groups nor did a stretch for all the muscles used during the workout. C5 excluded exercises for the back, chest, and calves. C5 did encourage breathing and relaxing during the stretch however, did not hold all the stretches for at least 15 seconds and some of the stretches were not appropriate for the intended audience. In the cooldown, as in the warm-up, the celebrity group completed a more well-rounded stretch.

The mean time for the fitness expert group's stretch phase was five minutes, see Table 1. The fitness experts successfully achieved positive responses to three out of the 
six questions of the stretching phase. FEl's total cooldown time was four minutes and two out of the seven questions were answered successfully. FEl did not exercise all the major muscle groups nor performed a stretch for all the muscles used during the workout. FEl omitted exercises for the back and calf muscles. FE1 did encourage breathing but not relaxing, and chose appropriate stretches for the intended audience. FEl's stretches however, were not held for at least 15 seconds. FE2's total cooldown time was six minutes in which four out of the seven questions were positively answered. FE2 accomplished this by exercising all the major muscle groups however, did not stretch all the muscles used during the workout. Although FE2 encouraged both breathing and relaxing during the stretches, and chose appropriate stretches, the stretches performed were not held for at least 15 seconds. FE3's total cooldown time was five minutes. FE3 achieved positive responses to three out of the six questions on the Video Critique. FE3 demonstrated exercises for all the major muscle groups and stretched all the muscles used during the workout. FE3 also chose appropriate stretches. FE3 did not hold all the stretches for 15 seconds nor encouraged breathing or relaxing during the stretch. In the

cooldown, as in the warm-up, the fitness expert group failed to complete a well-rounded stretch.

\section{Overall exercise selection}

The overall exercise selection of the Video Critique assessed two variables; 1) whether the exercises chosen for the exercise phase were appropriate for the intended audience and 2) if more than one exercise was given for each muscle group. This section of the Video Critique was scored one point for "YES" and zero points for "NO". The results of the overall exercise selection can be found in Table 5.

Four out of five of the celebrities chose appropriate exercises during the exercise phase. None of the celebrities demonstrated more than one exercise for each major 
Table 5

Overall exercise selection scores for the celebrity and fitness expert groups of the Exercise Phase

Celebrity 1

Celebrity 2

Celebrity 3

Celebrity 4

Celebrity 5

Fitness Expert 1

Fitness Expert 2

Fitness Expert 3
Yes

Yes

Yes

No

Yes

No

Yes

Yes
No

No

No

No

No
No

No

Yes 
muscle group. $\mathrm{Cl}$ received one point for choosing appropriate exercises and zero points for not giving more than one exercise for each major muscle group. C2 received one point for choosing appropriate exercises and zero points for not giving more than one exercise for each major muscle group. C3 received one point for choosing appropriate exercises and zero points for not giving more than one exercise for each major muscle group. $\mathrm{C} 4$ received zero points for not choosing appropriate exercises and zero points for not giving more than one exercise for each major muscle group. $\mathrm{C} 5$ received one point for choosing appropriate exercises and zero points for not giving more than one exercise for each major muscle group. In this case, it is clear to see that although the exercises chosen were generally safe, the instructors did not give the participant many choices.

Two out of the three fitness experts chose appropriate exercises during the exercise phase. One out of the three fitness experts demonstrated more than one exercise for each major muscle group. FE1 received zero points for not choosing appropriate exercises and zero points for not giving more than one exercise for each major muscle group. FE2 received one point for choosing appropriate exercises and zero points for not giving more than one exercise for each major muscle group. FE3 received one point for choosing appropriate exercises and one point for giving more than one exercise for each major muscle group.

\section{Overall presentation}

The overall presentation section of the Video Critique assessed six variables of the exercise phase. The variables were choreography, music selection, ability of the instructors to explain their actions, ability to make their instructions easy to understand, production quality, and motivation. These variables were rated on a scale from one to four, one being the lowest possible rating, four the highest. Figure 3 graphically represents the mean rating for all six variables for the celebrity and fitness expert groups 


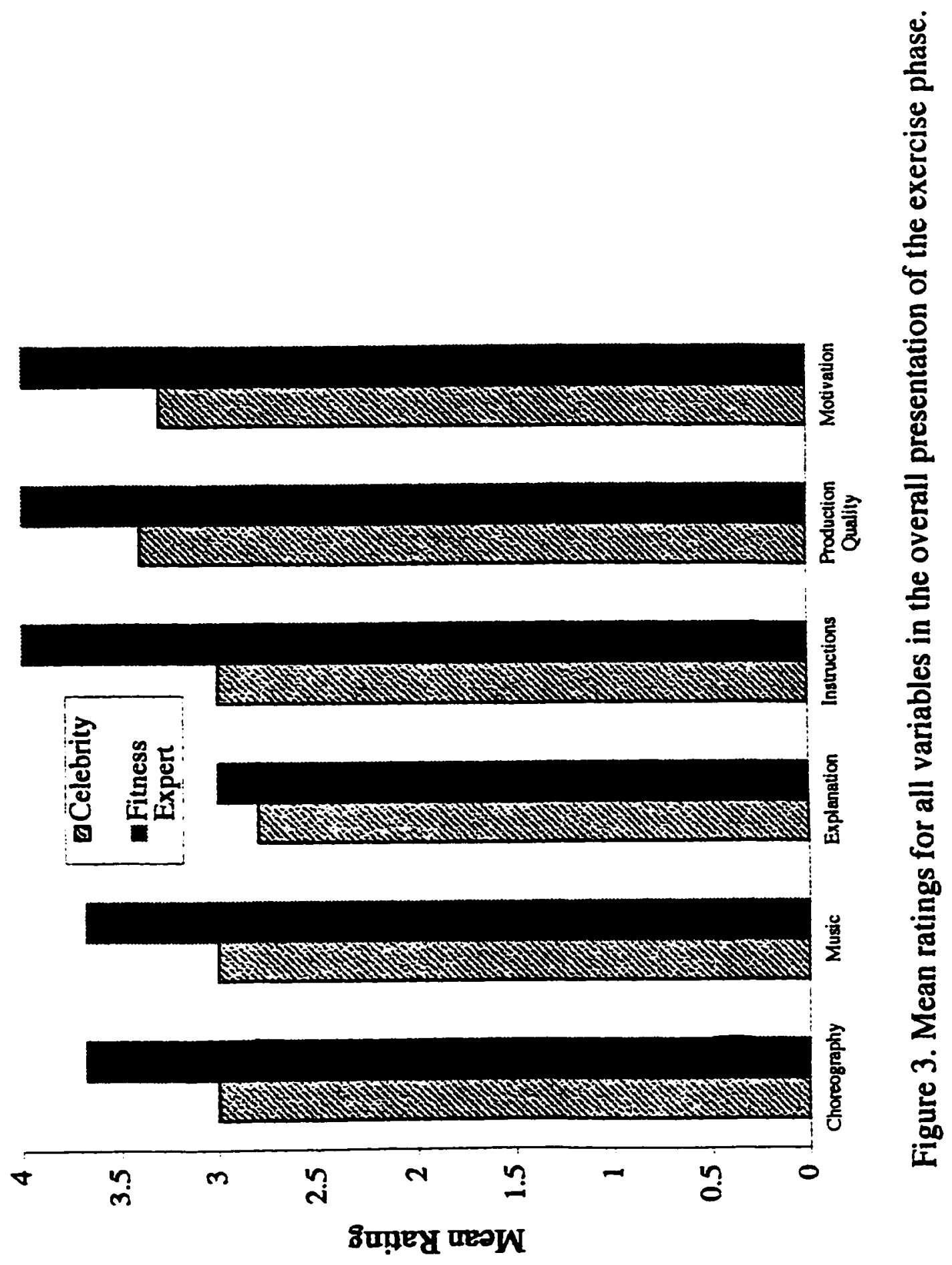


during the exercise phase.

The celebrity group received a mean rating of 3.0 for choreography of the exercises and 3.0 for music selection. The celebrity group also received a mean rating of 2.8 for the ability to explain the muscles as they related to the specific exercise, however, they received a mean rating of 3.0 for delivering easy to understand instructions. The celebrity group received a mean rating of 3.4 for production quality and 3.3 for motivational skills.

$\mathrm{Cl}$ received a rating of 3.0 for choreography of the exercises, for the choice of music, and the production quality of the videotape. $\mathrm{Cl}$ 's rating was 4.0 for explaining the exercises related to the muscle groups, 4.0 for the ability to deliver clear and understandable instructions, and 4.0 for motivational skills. C2 received a rating of 3.0 for the choreography of the exercises, the choice of music, and for motivational skills. C2 was rated 2.0 for explaining the exercises related to the muscle groups and 1.0 for the ability to deliver understandable instructions. However, $\mathrm{C} 2$ had a score of 4.0 for the production quality of the videotape. C3 was rated 3.0 for choreography of the exercises, the choice of music, and explaining the exercises related to the muscle groups. $\mathrm{C} 3$ received a rating of 4.0 for the ability to deliver understandable instructions, 4.0 for the production quality of the videotape, and 4.0 for motivational skills. C4 was rated 2.0 points for choreography of the exercises, 3.0 for the choice of music, and 3.0 for explaining the exercises related to the muscle groups. C4's rating was 3.0 for the ability to deliver understandable instructions, the production quality of the videotape, and for motivational skills. C5 was rated 4.0 for choreography of the exercises, 3.0 for choice of music, and 2.0 for explaining the exercises related to the muscle groups. C5 received a rating of 3.0 for the ability to deliver understandable instructions, 3.0 for the production quality of the videotape, however, only 2.5 for motivational skills. 
The fitness experts mean rating for choreography of the exercises as well as for music selection was 3.68. The fitness experts mean rating for correlating the muscles being exercised to the actual exercise was only 3.0. However, the fitness experts received a rating of 4.0 for delivering easy to understand instructions, 4.0 for the production quality of the videotape, and 4.0 for their motivational skills. The fitness experts were superior to the celebrity group in their abilities to instruct, teach, and motivate.

FEl was rated 3.0 for choreography of the exercises, 3.0 for the choice of music, and 3.0 for explaining the exercises related to the muscle groups. In addition, FE1 received a rating of 4.0 for the ability to deliver clear instructions, the production quality of the videotape, and for motivational skills. FE2 was rated 4.0 for choreography of the exercises, the choice of music, the ability to deliver understandable instructions, the production quality of the videotape, and for motivational skills. FE2 received a rating of 3.0 for explaining the exercises related to the muscle groups. FE3 was rated 4.0 for choreography of the exercises and the choice of music. In addition, FE3 received a rating of 4.0 for the ability to deliver clear and understandable instructions, 4.0 for the production quality of the videotape, and 4.0 for motivational skills. FE3 was only rated 3.0 for explaining the exercises as they related to the specific muscle groups.

\section{General comments}

The Video Critique allowed the researcher to make notes of interest and concern related to information provided during the viewing of the exercise videotapes. The following represent comments made during the observation of each videotape.

Celebrity \#1 did not perform any of the exercises during the conditioning phase of the workout but did give very detailed instructions of the exercise as it was demonstrated by the students. The instructor also appeared unprofessional at times when her hair 
covered her face while she was talking. This became a distraction. The choice of camera angles were inappropriate in a few areas. The exercises could have been demonstrated just as effectively in another manner.

Celebrity \#2 did not do anything that would injure anyone, however, the instructor did moves and exercises unfamiliar to the researcher. Furthermore, $\mathrm{C} 2$ provided no explanation as to the function or value of these moves or exercises. The instructor appeared nervous and seemed to be reading cue cards. The background students had better form and technique than the instructor.

Celebrity \#3 led one of the only two all muscle toning videotapes. The videotape was separated into two sections, both to be completed together or on consecutive days for a complete workout. C3's performance of the exercises improved in the second portion of the workout. In addition, the instructor gave a lengthy general discussion prior to the workout regarding exercise and health. The opinion of the researcher is that the discussion was focused on women but was nonetheless informative and accurate. The information was co-authored by an exercise physiologist with a doctoral degree. The coauthor is also a contributing editor to several professional group exercise instructor magazines as well as a contributing researcher in the field of exercise physiology.

Celebrity $\# 4$ did not teach or lead the exercises. The actual instructor on the videotape leading the exercise routine was a competitive dance aerobic champion. The videotape was designed for a young audience of 20-25 year old females. The inappropriate actions and inappropriate clothing however, led the researcher to believe it was designed for a young male audience. The poor choice of camera angles at various times, some having nothing to do with the exercises being presented, also confirmed this observation. An older population may find this exercise videotape demeaning and could erroneously stereotype group exercise instructors as unprofessional, thereby not giving 
credence to the credentialed instructors.

C5's videotape was one of the two exclusively dedicated to muscle toning. Full body muscle toning was the focus of celebrity $\# 5$ 's videotape, as described on the cover. However, upon review, the instructor did not use any resistance equipment for any of the exercises performed. According to McArdle et al. (1991), for a muscle to improve (get stronger) it needs to overcome a fixed resistance. The weight of one's arm or leg is not sufficient enough to accomplish improvement. Furthermore, the instructor did not offer any suggestions for using any type of resistance training once the participant's strength increased.

Fitness expert \#l attempted to accomplish a complete workout in 30 minutes, including cardiovascular conditioning and muscular conditioning. The physiological benefits are limited under these circumstances. This 30 minute exercise videotape, therefore, had shortcomings; the muscle conditioning segment was only nine minutes in length, the shortest muscle conditioning segment of all the exercise videotapes evaluated in this study. Though the videotape package led one to believe it was a full body workout, it in fact did not include exercises for two major muscle groups. In addition, the time spent on the exercises that were demonstrated was limited, reducing the opportunity of achieving muscle fatigue and consequently reduced the possibility of improved muscle tone.

Fitness expert \#2's videotape was performed by a fitness expert, however, a celebrity exercised alongside the expert and only interjected comments about the routine. The videotape cover advertised the celebrity as the leader, whereas the fitness expert actually led the program. Essentially, fitness exper $\# 2$ was disguised as a celebrity but was actually a fitness expert. The fitness expert was perfect in her execution, demonstrating to the viewer the lack of ability on the part of the celebrity involved. The 
fitness expert however, did fail to provide an adequate warm-up and cooldown.

Fitness expert \#3 was fun to watch, however, the exercises could prove to be intimidating and complicated for the average person. From the beginning of the warm-up, through the toning section and into the stretch phase the exercises were evaluated to be far too complicated for unfit or beginning level participants. The choice of moves and exercises involved complicated hand and foot patterns. This instructor was the only one that provided more than one exercise for each major muscle group. The instructions in the stretch phase were very detailed, thorough, and easy to understand. This was the only fitness expert videotape that was designated exclusively to muscle toning.

\section{Summary of Celebrity and Fitness Expert groups}

The celebrity group's strength was the warm-up phase. The celebrity group provided a 54 second longer warm-up than the fitness expert group. The celebrity group's stretch portion of the warm-up was 1 minute, 20 seconds longer than the fitness expert group. The celebrity group included 15\% more stretches during the stretch phase of the warm-up compared to the fitness expert group. This is a noticeable difference between the groups. The fitness expert group's active portion of the warm-up was only 28 seconds longer than the celebrities, a difference that does not appear to be meaningful. The fitness expert group executed the active warm-up with more accuracy and clarity than the celebrity group. The fitness expert group also executed the stretch portion, though limited in scope, with better form and alignment skills than the celebrity group.

The fitness expert group's overall presentation of the warm-up, cueing ability, appearance, and voice exceeded the celebrity group. The fitness expert group's skill of presentation proved to be more professional than their celebrity counterparts.

The fitness experts excelled during the exercise phase. The fitness expert group's exercise phase was 4 minutes 6 seconds longer than the celebrity group enabling them to 
include 2.2 more exercises than the celebrity group in their routine. The fitness experts also were more accurate in their execution of the exercises. The fitness expert group's alignment, form and technique, and cueing was more accurate than the celebrity group. Interestingly though, the celebrity group were better at choosing exercises appropriate for the audience than the fitness experts. However, the fitness experts were better at providing more choices of exercises than the celebrity group.

Just as the fitness experts were weak in the warm-up phase, the cooldown and stretch phase were also weak. The celebrity group allowed for $\mathbf{4 8}$ seconds more during the cooldown and consequently met more of the criteria than the fitness experts.

In all areas of the overall presentation, the fitness experts out performed the celebrity group. The fitness experts were better at both choreographing the exercise routine and choosing the appropriate music. The fitness experts were also able to explain a particular exercise as it related to a specific muscle group with more skill. The fitness experts were easier to understand. The production quality of the videotape was also $15 \%$ finer. And lastly, the fitness experts were perceived to be more motivating than the celebrity group.

Based on the three fitness expert's exercise videotapes evaluated in this research, the fitness experts delivered accurately executed workouts. Although the warm-up, for two of the fitness experts were partial in scope, the fitness experts were unmatched in their ability to demonstrate, teach, and explain all the exercises of the workout. It appears very curious that so few fitness experts' exercise videotapes were available in the popular major videostores to be evaluated in this research study.

Summary of the four top ranked videotapes

Each videotape analysis provided the researcher the opportunity to calculate an overall points achieved. The top four ranked videotapes, based on the grand total points 
achieved, were, in descending order: FE3, with 111.96 points, FE2, with 108.70 points, FEl with 107.43 points, and $\mathrm{Cl}$ with 96.39 points. A large difference in points achieved existed between the fitness expert videotapes and the celebrity videotapes. The common feature for success of these four videotapes was execution. Throughout the workout the movements were shown with a high level of skill. Based on the analysis of the data, the celebrity videotapes lacked in the overall presentation of the Video Critique.

The fitness expert of the top ranked videotape excelled in the area of form and technique of the exercises. Every movement was executed perfectly. The exercise phase was almost flawless. Even though the instructor performed only a partial stretch phase, the exercise phase was very complete, interesting, and appropriate for the intended audience. The overall presentation was of the highest quality. The professionalism of the fitness expert, the camera work and actual videotaping, the instructor's tone of voice and skill were superb. Though the workout was not simple, it was challenging and could keep an audience interested. The challenging aspect of an exercise program is very important for maintaining exercise adherence.

The main intent of this study was to evaluate and compare fitness experts leading exercise routines and celebrities leading exercise routines to determine their accuracy and usefulness of training principles and safety for the general population. It is almost impossible to determine the quality of an exercise videotape reading the videotape package. The public may not recognize the name of a trained fitness expert but may recognize a celebrity's name. This study showed that celebrities frequently used a fitness expert to validate their exercise videotape, however, the public may not recognize the fitness expert and the expertise they offer. The celebrity gains credibility through movies, magazines, and other high profile media venues. On the other hand, the fitness experts gain credibility for their skill through certification and professional training. 
This study has shown that the professionally trained fitness experts produced a more accurate workout and videotape, although the celebrities may have surpassed the fitness experts in one area. Some celebrities performed at a level close to that of the fitness experts although the celebrity group's overall presentation pales in comparison. However, the media and its emphasis on glamour and celebrity status may influence the type and quality of exercises viewed by the American public.

Given that the public may not recognize a high quality exercise videotape, this study attempted to provide guidelines for the future development of exercise videotapes based on the best aspects of the top four videotapes evaluated.

To assure that resistance training exercise videotapes are safe, useful, and accurate, all the essential training components must be included. The videotapes must include an appropriate warm-up; one that prepares the body for the exercises to follow. The warm-up must include stretches, performed actively or statically, for all the major muscle groups. The warm-up should be followed by an exercise segment that includes at least two different exercises for each major muscle group. Variations and modifications of exercises should be provided and demonstrated by the instructor leading the workout. The exercises should be performed from large to small muscle groups. The exercise segment should be followed by a cooldown that provides an adequate stretch of the muscles previously contracted. The stretch should be of ample length to allow the muscles to elongate in order to achieve flexibility within the muscle group. In addition, the exercises should be presented by persons who exhibit the ability to explain, demonstrate, and educate the participant in a manner that will enable the most novice of exercisers to achieve success.

Specifically, the warm-up needs to be active, or rhythmic in nature, (ACSM, 1991), to increase core body temperature, and include stretches, performed actively or 
statically, of muscles to be used during the workout. Skill of execution of the desired movements and the ability to explain and demonstrate them are significant to the quality of the presentation.

The exercise phase needs to include exercises for the whole body according to the workout description. A "total body workout" should include exercises for all the major muscle groups of the body. The workout should include exercises for the lower and upper torso creating muscle balance by working agonist and antagonist muscles. These muscles groups include legs, upper and lower portion, chest, back, shoulders, triceps, biceps, and abdominals. Preferably, the workout should include at least one exercise for each of these muscle groups in order to develop the muscles completely. The top exercise videotapes evaluated in this study provided this type of workout. The length of time of the videotape is a determining factor in providing an adequate number of exercises for the workout. The shorter length videotapes did not include at least one exercise for each muscle group. In fact, some muscle groups were simply omitted.

The cooldown phase should include stretches for all the major muscle groups. The stretches should be held for at least 10 seconds, with an average of 15-20 seconds, in order to elongate the muscles, create joint flexibility and improve range of motion. It also aids in alleviating muscle soreness.

An important aspect of any workout, and especially exercise videotapes is providing one that fits the target market. Advanced workouts should be labeled as such, as should intermediate and beginner level exercise videotapes, and they should then fulfill that description. Without direct supervision, as is the case when exercising to these videotapes at home, it is critical that the participant work at a level that is comfortable and appropriate. The participant can increase the level of intensity as their strength and ability improves. 


\section{CHAPTER V}

\section{CONCLUSIONS, SUMMARY, AND RECOMMENDATIONS}

\section{Summary}

The purpose of this study was to analyze and compare resistance training exercise videotapes led by fitness experts and celebrities for accuracy of training principles. A Video Critique was developed by the researcher based on the principles of training to evaluate the exercise videotapes. The Video Critique allowed the researcher to determine the accurate use of training principles, and compare the fitness expert group's videotapes to the celebrity group's videotapes to identify similarities and differences. Popular major video stores from a large metropolitan area were the source of the exercise videotapes. Of the 38 exercise videotapes found that met the criteria for selection, a random sample produced only three fitness expert videotapes. A total of eight exercise videotapes, five celebrity videotapes and three fitness expert videotapes, were evaluated. Three out of the eight exercise videotapes focused on muscle conditioning exclusively. The remaining exercise videotapes included aerobic conditioning prior to the muscle conditioning portion of the videotape. The Video Critique evaluated only the muscle conditioning portion of the exercise videotapes. The Video Critique assessed the inclusion and composition of the warm-up phase, the muscle conditioning exercise phase, and the cooldown'stretch phase. The Video Critique also determined the effectiveness and the instructor's accuracy in using the principles of training during the presentation of the exercises and other related information.

The fitness experts received higher ratings than the celebrities in their presentation of all the exercises and the execution of the movements in all the phases evaluated. Though the fitness experts failed to meet all the requirements of a safe and appropriate stretch in the warm-up phase, the active phase of the warm-up was sufficient. 
The celebrities were much more accurate in choosing appropriate stretches in the warmup, but their active phase of the warm-up lacked the poise, style, and execution demonstrated by the fitness experts. Similar results were found in the cooldown/stretch phase. The fitness experts did not provide a quality cooldown/stretch whereas the celebrities, once again, excelled in this area. The fitness experts were adept in their exercise phase, delivering clear instructions and providing easy to follow demonstrations. The exercise phase of the fitness experts was more than four minutes longer than the celebrities. This provided for a greater exercise selection and a more thorough workout., Based on a total points achieved on the Video Critique, the fitness expert group's exercise videotapes were the top ranked videotapes.

\section{Conclusions}

The conclusions that can be drawn from this study are:

1. The celebrity group provided a more complete warm-up and cooldown/stretch phase of the exercise program compared to the fitness experts.

2. The celebrity group, though not as skilled as the fitness experts in the delivery or presentation of the information, did nothing that would cause harm to the general public.

3. The celebrity group and fitness expert group both explained the format of the exercise program in their introduction and made suggestions for the novice exerciser.

4. Both the celebrity group and the fitness expert group followed the protocol of including a warm-up before the beginning of the exercise program and included a stretch at the conclusion of the exercise program.

5. The fitness experts excelled in their ability to explain and demonstrate exercises in a way that would make it simple for the general public to understand and follow, during the warm-up, exercise, and cooldown phases. 
6. The fitness experts performed exercises in a more interesting manner, allowing the viewers interest to remain high.

7. The fitness experts provided a thorough muscle conditioning routine with more exercises and dedicated more time to the workout.

8. The fitness experts presented themselves in a professional manner, that is, the fitness experts chose appropriate camera angles, appropriate attire, and displayed behavior that did not distract the viewer from the exercises.

9. There were a limited number of fitness expert exercise videotapes in popular major videostores.

\section{Recommendations for Future Research}

Based on the results of this study, the following recommendations for future research include:

1. Based on the curious phenomenon of only finding three exercise videotapes by fitness experts, future studies need to broaden the selection of videotapes to include exercise videotape catalogs.

2. To evaluate exercise videotapes led by men, celebrities and fitness experts.

3. Replicate this study with a larger sample size.

4. To determine the effectiveness and accuracy of muscle conditioning exercise videotapes that focus on one, two, or three specific muscle groups.

5. To revise the Video Critique so as to separate the hip flexor stretch from the quadriceps stretch during the stretch phase of the evaluation.

6. To revise the Video Critique so as to limit voice evaluation to enunciation only.

7. To revise the Video Critique to clarify the definition of physique. 
8. To revise the Video Critique so as to include a separate rating for identifying whether the muscle group for the exercise being shown during the exercise phase evaluation was chosen correctly or incorrectly.

9. To expand and be more precise in the definition of motivation in the Video Critique.

10. To revise the Video Critique to include a section that allows the researcher to identify the difficulty level of the exercise videotape and the audience the videotape is intended. 


\section{REFERENCES}

American College of Sport Medicine. (1990). The recommended quantity and quality of exercise for developing and maintaining cardiorespiratory and muscular fitness in healthy adults. Medicine and Science in Sports and Exercise, 22(2), 265-273.

American College of Sports Medicine. (1991). Guidelines for exercise testing and prescription (4th ed.). Philadelphia: Lea \& Febiger.

Baker, J. (1994, May/June). Resistance training basics. American Fitness, pp. 26-29.

Blair, S.N., Kohl, H.W., Paffenbarger, R.S., Clark, D.G., Cooper, K.H., \& Gibbons, L.W. (1989). Physical fitness and all-cause mortality. Journal of the American Heart Association, 262(17), 2395-2401.

Cinque, C. (1990). Women's strength training. The Physician and Sports Medicine, 18(8), 123-128.

Colorado, S. (1994, September). Flexibility, the final frontier. Paper presented at a lecture for the ACSM exercise leader workshop and certification, San Jose, CA.

Durrett, A. (1995, May). Our bodies ourselves. Idea Today, pp. 33-39.

Dvorak, J. (1994, January/February). Time for a change. American Fitness, pp. 38-39, 58.

Hargarten, K. (1994). Menopause - how exercise mitigate symptoms. The Physician and Sports Medicine, 22(1), 49-56.

Hurley, B.F., Hagberg, J.M., Goldberg, A.P., Seals, D.R., Ehsani, A.A., Brennan, R.E., \& Holloszy, J.O. (1988). Resistive training can reduce coronary risk factors without altering VO2max or percent body fat. Medicine and Science in Sports and Exercise, 20(2), 150-154. 
Hurley, B.F., Seals, D.R., Ehsani, A.A., Cartier, L-J, Dalsky, G.P., Hagberg, J.M., \& Holloszy, J.O. (1984). Effects of high- intensity strength training on cardiovascular function. Medicine and Science in Sports and Exercise, $16(5), 488-493$.

Johnston, G. (1995, May). Creating a healthy body image. Idea Today, pp. 40-42. Kase, L.M. (1991, April). Lift weight to lose it. Vogue, pp. 222-224.

Kosich, D. (1994, June). What a beginner needs to know about strength training, nutrition and aerobic fitness. Lecture presented at the IDEA Convention, Las Vegas, Nevada.

Kravitz, L. (1992). Anybody's guide to total fitness (3rd ed.). Dubuque: Kendall/Hunt.

Kravitz, L. (1994, January). The facts of muscle. Idea Today, pp. 30-33.

Kravitz, L., \& Robergs, R. (1995, October). Is it genetic? Idea Today, pp. 70-76.

Marcus, R., Drinkwater, B., Dalsky, G., Dufek, J., Raab, D., Slemenda, C., \& Snow-Harter, C. (1992). Osteoporosis and exercise. Medicine and Science in Sports and Exercise, 24, 301-307.

McArdle, W.D., Katch, F.I., \& Katch, V.L. (1991). Exercise physiology (3rd ed.). Philadelphia: Lea \& Febiger.

McGinnis, M.J. (1992). The public health burden of a sedentary lifestyle. Medicine and Science in Sports and Exercise, 24(Suppl. 6), 196-200.

Melnick, M.J., \& Mookerjee, S. (1991). Effects of advanced weight training on body-cathexis and self-esteem. Perceptual Motor Skills, 72, 1335-1345.

Mersy, D.J. (1991). Health benefits of aerobic exercise. Postgraduate Medicine, 90 , $103-110$.

Paffenbarger, R.S., Hyde, R.T., Wing, A.L., \& Hsieh, C.C. (1986). Physical activity, allcause mortality, and longevity of college alumni. New England Journal of 
Medicine, 314, 605-613.

Pilgrim, P. (1995, February). Balancing exercise with relaxation. Idea Today, pp. 32-37.

Rogers, M.A., \& Evans, W.J. (1993). Changes in skeletal muscle with aging: effects of exercise training. Exercise and Sport Science Reviews, 21, 65-102.

Sacra, C. (1994, February). Bodybuilding blues. Shape p. 20.

Samples, P. (1990). Exercise encouraged for people with arthritis. The Physician and Sports Medicine $18(1), 122-127$.

Sharp, C. (1994, January). Industry news: osteoporosis. Idea Today, p. 23.

Staff. (1993, September). Never too late to build up your muscle. Tufts University Diet and Nutrition Letter, p. 6-7.

Staff. (1994, June). The bare-bones facts for avoiding osteoporosis. Tufts University Diet and Nutrition Letter, p. 3-5.

Staff. (1993, July). A lifelong program to build strong bones. UC Berkeley Wellness Letter p. 4.

Staff. (1993, November). An easy-to-swallow prescription. UC Berkeley Wellness Letter, p. 6.

Staff. (1993, December). The new American body. UCB Wellness Letter, p. 1-2.

Todd, W. (1991). Weight training: the heart of the matter. Scholastic Coach, 60(6), 116-117.

Tollison, D.C., \& Kriegel, M.L. (1990). Bone loss and physical activity: can exercise prevent osteoporosis? The Journal of the South Carolina Medical Association, 86(3), 138-140.

Urbanska, W. (1994, March). The body-image report. Shape, pp. 73-74, 127128.

Yeager, K., Agostini, R., Nattiv, A., \& Drinkwater, B. (1993). The female 
athlete triad: Disordered eating, amenorrhea, osteoporosis. Medicine and Science in Sports and Exercise, 25(7), 775-777. 
APPENDIX A

VIDEO CRITIQUE 


\section{VIDEO CRITIOUE}

\section{VIDEO TITLE:}

INSTRUCTOR:

\section{Yes}

No

Did the instructor introduce him/herself?

Did the instructor explain the format of the workout?

1

0

1

0

\section{WARM-UP}

ACTIVE PHASE:

RATING

\section{TOTAL TIME:}

Execution

Active:

Clean and sharp movements

Stretch:

Clear demonstration of action desired

$\begin{array}{llll}4 & 3 & 2 & 1 \\ 4 & 3 & 2 & 1\end{array}$

Alignment

Spinal alignment

Hip to ankle alignment

$\begin{array}{llll}4 & 3 & 2 & 1 \\ 4 & 3 & 2 & 1 \\ 4 & 3 & 2 & 1\end{array}$

Range of motion

Choice of moves

Appropriate for audience

Meets design of the workout

$\begin{array}{llll}4 & 3 & 2 & 1 \\ 4 & 3 & 2 & 1\end{array}$


STRETCH PHASE:

Shoulders

Upper back

Lower back

Hip flexor/quads

Hamstrings

Calves

Chest
EXECUTION

YES NO

RATING

$\begin{array}{llllll}1 & 0 & 4 & 3 & 2 & 1 \\ 1 & 0 & 4 & 3 & 2 & 1 \\ 1 & 0 & 4 & 3 & 2 & 1 \\ 1 & 0 & 4 & 3 & 2 & 1 \\ 1 & 0 & 4 & 3 & 2 & 1 \\ 1 & 0 & 4 & 3 & 2 & 1 \\ 1 & 0 & 4 & 3 & 2 & 1\end{array}$

\section{RATING}

Cueing

$\begin{array}{llll}4 & 3 & 2 & 1\end{array}$

Voice

Tone

Annunciation

Music Selection

$\begin{array}{llll}4 & 3 & 2 & 1 \\ 4 & 3 & 2 & 1 \\ 4 & 3 & 2 & 1\end{array}$

Type:

Appearance

Clothes

Physique

Enthusiasm

Camera Angles

$\begin{array}{llll}4 & 3 & 2 & 1 \\ 4 & 3 & 2 & 1 \\ 4 & 3 & 2 & 1 \\ 4 & 3 & 2 & 1\end{array}$


EXERCISE PHASE*

* Exercises are reviewed in order of appearance

EXERCISE

Equip used
MUSCLE

Total
Alignment Form $\quad \underline{\text { Cueing }}$

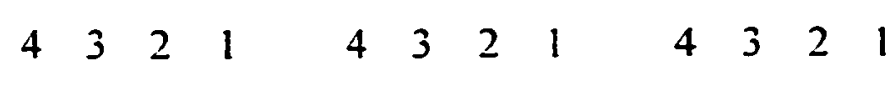

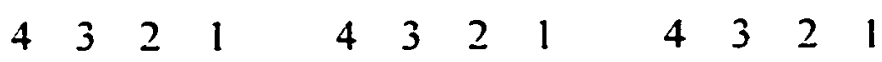

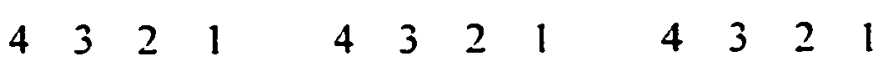

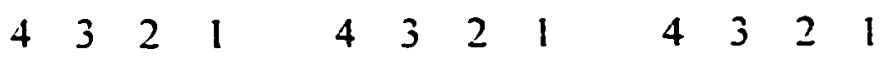

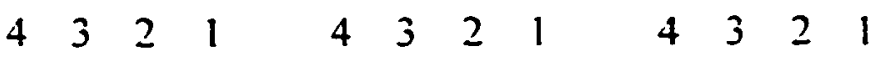

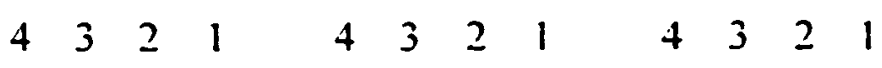

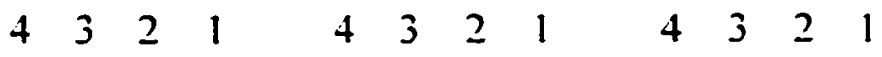




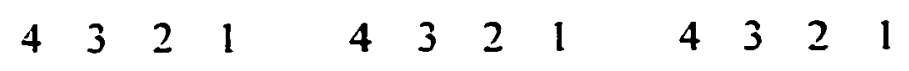

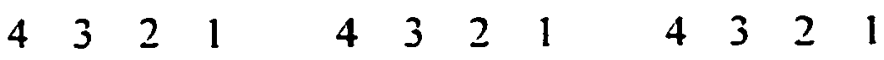

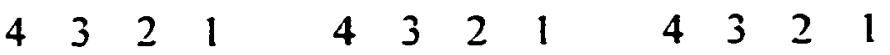

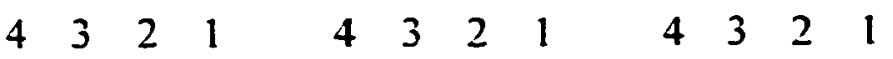

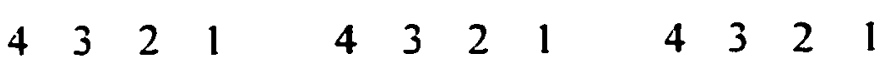

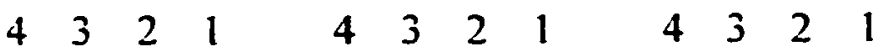

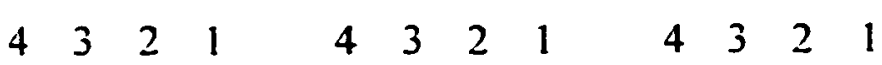

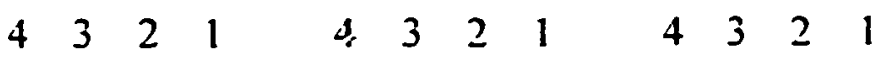

$\begin{array}{llllllllllll}4 & 3 & 2 & 1 & 4 & 3 & 2 & 1 & 4 & 3 & 2 & 1\end{array}$

$\begin{array}{llllllllllll}4 & 3 & 2 & 1 & 4 & 3 & 2 & 1 & 4 & 3 & 2 & 1\end{array}$

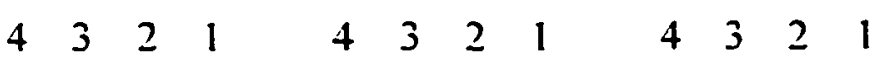

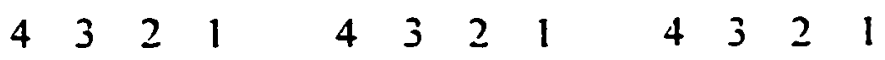




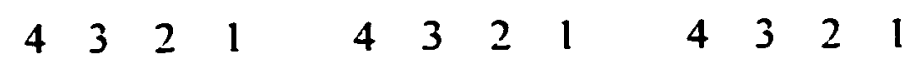

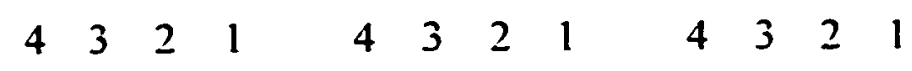

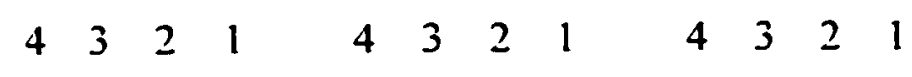

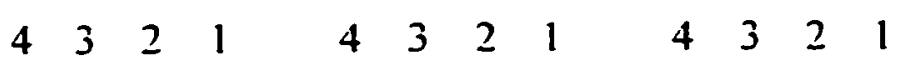

Grand total:

Average:

\section{COOLDOWN/STRETCH}

TIME:

YES NO

All major muscles exercised?

Were exercised muscle stretched?

Were stretches held for at least 15 seconds?

$\begin{array}{ll}1 & 0 \\ 1 & 0 \\ 1 & 0\end{array}$

Stretching instructions:

Encouraged breathing?

Encouraged relaxing for stretch?

10

Were all the stretches appropriate?

RATING

OVERALL EXERCISE SELECTION

Were the exercise choices appropriate to audience

1

0 
More than one exercise given for each major muscle

OVERALL PRESENTATION

Choreography of exercises

Music selection

Explanation of which muscles were

being exercised

Instructions were easy to understand

Production quality

Was the instructor motivating?

\section{RATING}

$\begin{array}{llll}4 & 3 & 2 & 1 \\ 4 & 3 & 2 & 1\end{array}$

$\begin{array}{llll}4 & 3 & 2 & 1 \\ 4 & 3 & 2 & 1 \\ 4 & 3 & 2 & 1 \\ 4 & 3 & 3 & 1\end{array}$

\section{RATINGS:}

Excellent $=4$

Good $=3$

Fair $=2$

Poor $=1$

Absent $=0$ 


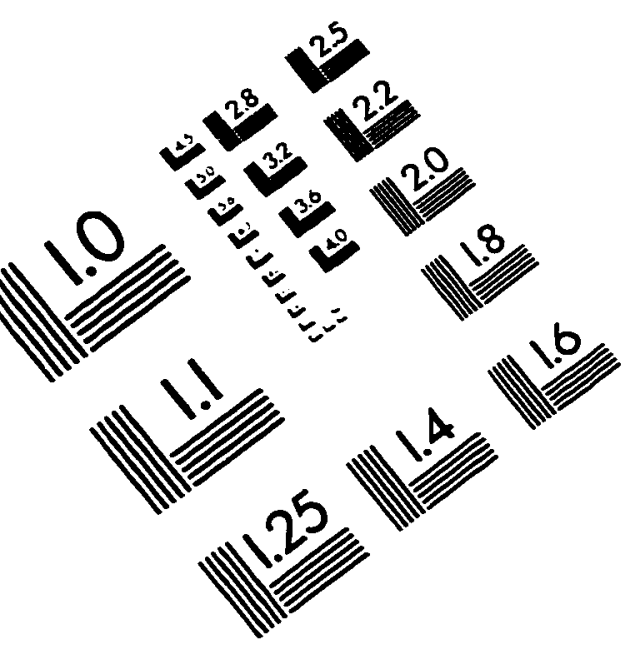

\section{IMAGE EVALUATION TEST TARGET (QA-3)}
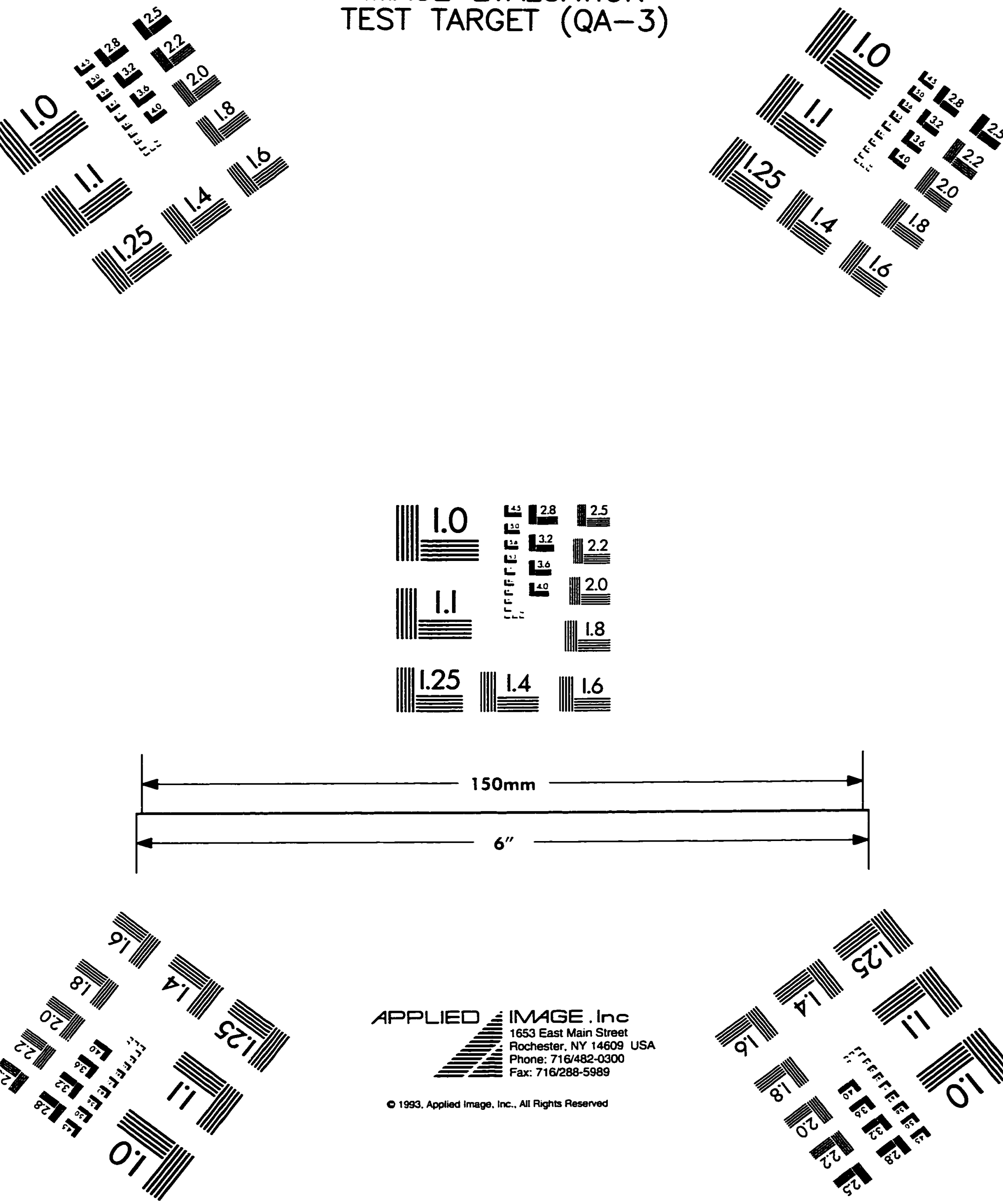